Ogier 



\section{Oggero Spatacurta und Ogier le Danois}

\section{Zur Komplexität einer epischen Tradition}

Résumé : Pour évaluer les désignations et l'ancrage historique de ce personnage, il importe de confronter plusieurs données qui peuvent a priori sembler hétérogènes :

1) Dans une charte de 1063 (sinon de 1053), émanant de Guigues le Vieux, comte d'Albon ( Dauphiné), un témoin s'appelle Otgerius spata curta. Ce nom rappelle l'Oggero Spatacurta de la Nota Emilianense et prouve que non seulement l'Ogier épique lui-même, mais aussi son épée légendaire étaient connus dès le milieu $d u \mathrm{XI}^{\mathrm{e}}$ siècle dans un vaste territoire s'étendant au moins de la Rioja espagnole jusqu'en Dauphiné.

Ici, spata curta désigne le (scrama)sax ou semispatium du haut Moyen Âge, arme apte à frapper, piquer et même à éventrer, doté à l'origine d'une lame d'environ $25 \mathrm{~cm}$, puis d'environ $50 \mathrm{~cm}$ ou même un peu plus longue vers les $\mathrm{IX}^{\mathrm{e}}$ ou $\mathrm{X}^{\mathrm{e}}$ siècles. À cette dernière époque, elle cessa définitivement de faire partie de l'équipement du chevalier au profit de l'épée classique, désormais unique arme de taille, à lame d'environ $65-80 \mathrm{~cm}$. Parallèlement, le terme spata curta devait prendre une connotation de 'pré-chevaleresque, farouche'.

2) Le duc Audgarius des années 752-771, 'spécialiste' des relations avec le pape sous Pépin, détenteur de biens fiscaux à l'ouest de Paris probablement déjà sous Pépin, certainement sous Carloman, est quasiment indissociable de la mention de Ga(i)llardon dans la Chevalerie Ogier. C'est bien lui le modèle principal de l'Ogier épique.

3) Pourquoi alors Ogier le Danois ou de Denemarche/Danemarche ? Il n'est guère possible de dissocier le viking Oscheri dux (< anc. norrois Ásgeirr ; cf. anc. angl. Osgar), qui sévissait surtout dans l'ouest de la France de 841 à 851, notoire comme destructeur de Beauvais, d'Ogier 'le Danois', destructeur de Beauvais dans la Chevalerie.

4) Le roi danois Gøtrik (ou peut-être Guðfrið/Guðrøð, le nom vernaculaire étant difficile à restituer), ennemi de Charlemagne, Godofridus dans les sources latines contemporaines, est devenu le roi danois Gaufrei/Gaufroi, père d'Ogier dans la Chevalerie.

5) Enfin, l'indéniable polarité inhérente à l'Ogier épique - loin de nécessiter l'hypothèse de deux Ogier francs, l'un conseiller intime, l'autre ennemi de Charlemagne - s'explique par l'isolement progressif auto-imposé de l'Ogier historique, reconnu par la plupart de ses compatriotes comme hautement honorable, mais aussi comme tout à fait contraire à la raison d'État.

Als im Jahre 1953 die Romanistik in der Nota Emilianense einen Oggero Spatacurta als Paladin Karls des Großen kennenlernte, konnte dessen Identität mit dem Ogier le Danois der altfranzösischen Epik nicht zweifelhaft bleiben.

Anmerkung: Erstmals veröffentlicht in: Zeitschrift für romanische Philologie 120 (2004), 421-456.

○ Open Access. ๑ 2019 Gustav Adolf Beckmann, publiziert von De Gruyter. (cc)BY-NC-ND Dieses Werk ist lizenziert unter der Creative Commons Attribution-NonCommercial-NoDerivatives 4.0 Lizenz.

https://doi.org/10.1515/9783110615692-001 
Dennoch gab die neue Benennung der Forschung zwei Probleme auf: einmal führt Ogier sein Schwert Corte/Cortain noch nicht im Oxforder Roland, sondern erst in den jüngeren Fassungen von V4 an sowie im Fierabras, Agolant, Aspremont, Renaut de Montauban, in der Chevalerie Ogier und in anderen, noch späteren Epen; ${ }^{1}$ zweitens aber macht keine Chanson de geste und kein Dokument außer der Nota Emilianense aus dem Namen des Schwertes einen Beinamen seines Trägers. Wer der Nota eher skeptisch gegenüberstand, konnte in dem ersten Umstand ein Argument für deren möglichst späte Datierung, in dem zweiten ein Anzeichen für ein noch embryonales Stadium der Ogierlegende, ja für den peripher-provinziellen Charakter der Nota sehen. ${ }^{2}$

Andererseits hat Ramón Menéndez Pidal im Namen des Neotraditionalismus nicht gezögert, wie die anderen Angaben der Nota auch diese in einen großen Zusammenhang zu stellen:

«La Nota constitue, en outre, le premier témoignage connu sur l'épée légendaire d'Ogier, en dotant ce héros d'une épithète épique, Oggero Spatacurta. Un tel surnom manifeste un grand archaïsme dans le développement de la légende épique d'Ogier, puisqu'il n’apparaît plus dans les nombreuses chansons de geste postérieures, celles que nous connaissons aujourd'hui. Mais le caractère épique du surnom, au XI $\mathrm{X}^{\mathrm{e}}$ siècle, est tout à fait hors de doute aux yeux du traditionalisme, qui ne voit aucun motif pour refuser un entier crédit au témoignage de la Nota, d'autant qu'il est conforme à l'usage, pratiqué au cours du même siècle, des épithètes composées d'un substantif ou d'un adjectif; cet usage nous est attesté par l'apocryphe de Saint-Yrieix. On peut donc conjecturer que, dans les gestes françaises du XI ${ }^{\mathrm{e}}$ siècle, l'épithète Ogier Courte-Epée était d'usage courant (...).

Mais cette épée, qui fait sa première apparition dans la Nota Emilianense, ne réapparaît que cent ans plus tard; elle est alors nommée dans treize chansons de geste conservées. Il serait déraisonnable de supposer que ce fameux et vivant souvenir ne s'est réveillé dans la poésie qu'à la fin du XII ${ }^{\mathrm{e}}$ siècle. Nous savons qu'un Oggero Spatacurta, ou plutôt Ogier Courte-espée, intervenait dans le Roland représenté par la Nota; nous savons que l'Ogier du Roland des environs de 1100, privé de son épée courte, se sert d'une arme anonyme; nous savons enfin que l'Ogier du Roland rimé vers 1170 a recouvré sa Curtaine. Nier la continuité poétique entre le $\mathrm{XI}^{\mathrm{e}}$ et le $\mathrm{XII}^{\mathrm{e}}$ siècle, c'est fermer les yeux à la réalité et méconnaître l'histoire des remaniements épiques». ${ }^{3}$

1 Für die Nennungen in den späteren Versionen des Rolandsliedes cf. Alonso (1953, 14-19); R. Menéndez Pidal (1960, 140 ss.); Togeby (1969, 17, wo V 7 fehlt). Die Nennungen in anderen Epen findet man bei Moisan (1986, jeweils s. v. Co(u)rtain). Weniger umfassend und in bezug auf die benutzten Ausgaben teilweise veraltet, aber leichter zu handhaben und deshalb weiterhin wichtig bleibt Langlois (1904, hier s. v. Corte).

2 Vor allem Walpole (1956/7, 7 s.); Frank (1956, 226 ss.); nuancierter, aber im Prinzip ebenso Lecoy (1955, 256, 265 n. 1): Verdacht, das Epitheton Spata Curta könne einer lat. Vorlage entstammen und umgekehrt (269): «même en ce qui concerne les noms des personnages, il [le moine de San Millán] fait preuve d'une telle ignorance qu'il nous est bien difficile de faire fond sur ses affirmations».

3 Menéndez Pidal (1960), 417, 419. 
Wie man sieht, kann der Neotraditionalismus hier wie so oft den Gedanken einer geschichtlichen Kontinuität für sich als Wahrscheinlichkeitsargument in Anspruch nehmen; dennoch fehlt ein eigentlicher Beweis.

Ich glaube nun, mit Hilfe eines neuaufgefundenen Dokuments diese Lücke schließen, also die Kontroverse im Sinne Menéndez Pidals entscheiden zu können. Im Laufe einer größeren Untersuchung ${ }^{4}$ über das Vorkommen «epischer» Eigennamen in französischen und benachbarten Urkundensammlungen stieß ich im Kartular des nahe der Dora Riparia (also im heutigen Italien, aber noch im franko-provenzalischen Sprachgebiet) gelegenen Priorates von Oulx auf die folgende Urkunde:

«In nomine sancte et indiuidue trinitatis. Anno ab incarnacione domini M.L[X].III. Indiccione prima. Ego Guigo comes qui nomine uocor senex. atque filius meus Guigo pinguis dono et confirmo pro anime mee mercede et pro anima patris mei et matris mee et parentum meorum ecclesie beati petri cum ceteris apostolis et ecclesie sancti laurencii martiris in loco qui dicitur ple[b]s martirum mansum unum cum omnibus rebus ad se pertinentibus, iacet in loco qui dicitur sesana, et canonicis in supra nominatis ecclesiis regulariter uiuentibus et omnibus eorum successoribus. ut pro animabus nostris ipsi apud omnipotentem intercessores existant. quod totum factum est consilio domini ade castellani briençonis existentis. Interfuerunt testes quidam canonici. Girardus ualençole. Vidricus prepositus et uuarnerius. et martinus. Galterius: et quidam laici. Aurucius. Armannus presbiteralis. letardus crossus. Girardus garembo. Otgerius spata.(g.)curta. Cat(b)aldus diaconus». 5

Die Urkunde findet sich im ältesten erhaltenen, 1236 geschriebenen Kartular des Priorates sowie in den jüngeren, seit dem 16. Jh. entstandenen Kartularen, die zwar hier zur Textgestaltung nichts beitragen, doch immerhin nach dem Herausgeber Collino nicht Abschriften des ältesten Kartulars sind, sondern mit diesem eine origine comune haben ${ }^{6}$ sie erscheint demgemäß in praktisch identischer Form in den beiden Druckausgaben der Kartularüberlieferung von Oulx. Soweit ich bei sorgfältiger Nachprüfung habe feststellen können, ist sie noch von niemandem als gefälscht oder verfälscht bezeichnet worden, insbesondere nicht von den beiden bahnbrechenden Historikern der Region, A. de Terrebasse

4 Bei dieser noch nicht veröffentlichten Arbeit habe ich mich bemüht, die Gesamtheit des im Druck erschienenen Urkundenmaterials der Zeit von 778 bis 1150 aus dem französischen und provenzalischen Sprachgebiet sowie den angrenzenden Gebieten westlich des Rheins und nördlich des Ebro auszuwerten. Es handelt sich insgesamt um etwa 75.000 Urkunden und weitere 15.000 Regesten; ihre Durchsicht war selbstverständlich nur möglich, weil viele Urkundensammlungen, speziell neueren Datums, verläßliche Namenregister enthalten.

5 Collino (1908, 18). Ältere Ausgabe: Rivautella/Berta (1753, 135). Schon vorher war die Urkunde mit unbedeutenden Varianten abgedruckt worden bei Guichenon $(1660,177)$.

6 Collino (1908, IX). 
(1875) und G. de Manteyer (1925), die sie beide besprechen. ${ }^{7}$ Der ältere der beiden Donatoren, Graf Guigo Senex von Albon, tritt zu einem schlecht fixierbaren Zeitpunkt zwischen 1060 und 1075 in das Kloster Cluny ein und stirbt dort zwanzig Tage später; er heißt auch sonst im Unterschied zu seinem gleichnamigen Sohn Maior oder Vetus. Der jüngere Guigo muß um 1025 geboren sein, erscheint 1034 als Zeuge, 1050 als verheiratet und ist nach de Manteyer bis 1076/ 79 belegt; er führt auch sonst bereits in zeitgenössischen Quellen, und zwar in Urkunden seiner eigenen Familie, den Beinamen Crassus. ${ }^{8} \mathrm{Zu}$ einer Bemerkung Anlaß gibt nur der Umstand, daß das Jahr 1053 nicht mit der ersten Indiktion zusammenfiel. De Terrebasse und nach ihm Collino haben angenommen, im Archetyp der Jahreszahl sei versehentlich ein $X$ ausgefallen; die Datierung auf 1063 sei umso eher gerechtfertigt, als die wirkliche Existenz des Priorates erst durch die große Schenkung des Oddo und der Adelheid von Savoyen vom Jahre 1057 gesichert sei. De Manteyer hält demgegenüber an 1053 fest, vertritt also offenbar die Meinung, daß im Original die Indiktion VI stand, schon bei der Niederschrift des Archetyps aber das $V$ übersehen wurde. Wer mit der mittelalterlichen Diplomatik vertraut ist, weiß, daß solche Unfälle bei der Abschrift römischer Zahlen, insbesondere in der Datumzeile, alltäglich sind und bei weitem nicht ausreichen, eine Urkunde $\mathrm{zu}$ verdächtigen. Der belanglose Einzelbuchstabe $g$ zwischen spata und curta schließlich, den Collino zu Recht getilgt hat, ist wohl darauf zurückzuführen, daß der Schreiber zunächst ein falsches Adjektiv (oder eine falsche Graphie von curta) niederschreiben wollte, dann zwar seinen Fehler sofort erkannte, die Verbesserung jedoch bis zum Trocknen der Tinte verschob und anschließend vergaß.

Da ich den Beinamen spata curta trotz intensiver Bemühungen in einer Unzahl von Urkunden ${ }^{9}$ nie mit einem anderen Namen gekoppelt vorgefunden habe, kann ich es unmöglich als Zufall ansehen, daß er hier gerade wie in der Nota mit dem Namen Otgerius gekoppelt erscheint.

Frappant ist dabei zunächst die zeitliche Nähe zur Nota: selbst wenn wir die Datierung von de Terrebasse übernehmen und anerkennen, daß der Beiname vielleicht erst dem erwachsenen Zeugen beigelegt wurde, ist damit der Doppelname, wie er uns in der Nota entgegentritt, für das Jahr 1063 belegt, also gerade in der Mitte jenes dritten Viertels des 11. Jh., in welches Gonzalo und Ramón Menéndez Pidal ${ }^{10}$ die Nota datieren! Und da es über alle Maßen bizarr wäre,

7 De Terrebasse (1875, 55 ss.); de Manteyer (1908, 182-184; 1925, 36 ss., 81 n. 29 sowie Stammtafel der Grafen von Albon am Schluß des Buches).

8 De Terrebasse und Manteyer (wie vorige n.); cf. noch Gallia Christiana $(1865,82)$.

9 Cf. oben n. 4.

10 Gonzalo Menéndez Pidal (1958, 7-19); Ramón Menéndez Pidal (1960, 385-387). 
die Ausdrucksweise der Nota von dem unbekannten Laienzeugen aus den Westalpen oder von einem ebenfalls unbekannten, willkürlich postulierten Namensvorgänger abzuleiten, bleibt nur die eine Lösung, daß der Zeuge in Oulx seinen Beinamen dem «epischen» Ogier verdankt. Warum sollte man weiter mit dem obengenannten Argument die Datierung der Nota anzweifeln, wenn für den verdächtigen Ausdruck ein gleichzeitiges Zeugnis vorliegt? Aufgrund der großen Entfernung zwischen San Millán und Oulx aber wird man die gemeinsame Quelle beider mindestens in die Zeit um 1050 zurückverlegen müssen.

Noch wichtiger als der zeitliche scheint mir der räumliche Aspekt. Selbst wenn man ganz grundlos die Urkunde als eine Fälschung des ältesten Kartularschreibers und damit des Jahres 1236 ansähe, bliebe der für die individualistische Forschung fatale Umstand, daß die Benennung, in der man so schnell provinzielle Besonderheit erblicken wollte, in einer Entfernung von fast tausend Kilometern Wegstrecke ebenfalls bekannt war. Urteilte Ramón Menéndez Pidal zu streng, als er den Versuch, in der Nota Emilianense eine légende locale $\mathrm{zu}$ sehen, eine bien mauvaise échappatoire ${ }^{11}$ nannte? Und hätte er sich, wenn er unsere Urkunde gekannt hätte, besser ausdrücken können, als er es aufgrund einer lebenslangen Erfahrung mit epischen Texten tat?

\section{II}

In welchem Sinn charakterisierte nun in der zweiten Hälfte des 11. Jh. das Kurzschwert seinen Träger? Der gladius des römischen Legionärs war ein ziemlich kurzes Schwert ( $50 \mathrm{~cm}$ Klingenlänge); doch in der Spätantike ging Rom großenteils über zur spatha, dem Langschwert (65-80 cm Klingenlänge), das sich gegenüber hochgewachsenen oder berittenen Feinden besser bewährte ${ }^{12}$ und das dann als épée bis in die Neuzeit die «edelste» Waffe blieb. Im Merowingerreich freilich konnte sich nur eine Minderheit der Krieger ein Langschwert leisten; ${ }^{13}$ «Volkswaffe» war stattdessen die Frankiska-Axt, seit dem 6. Jh. dann das (scrama)sax oder semispatium, ein Kurzschwert, dessen Klingenlänge bis zum 8. Jh. allmählich von etwa $25 \mathrm{~cm}$ bis auf $55 \mathrm{~cm}$ und darüber zunahm. ${ }^{14}$ Doch auch die Wohlhabenden verschmähten lange Zeit neben der Spatha nicht das Kurzschwert: der Waltharius-Dichter schreibt (vv. 337 s.) Walter den Gebrauch beider Schwerter zu und bezeichnet das als ursprünglich hunnische Sitte; schon

11 Ramón Menéndez Pidal (1960, 392) mit Bezug auf Frank (1956 passim).

12 Cf. z. B. Der kleine Pauly s. vv. gladius, spatha; Lombard (1974, 98).

13 Cf. z. B. Lombard (1974, 91); Siegmund (1997, 700, 705).

14 Siegmund (1997, 700 ss.); Périn/Kazanski (1997a, 710 s.). Cf. schon Böhner (1958, 130-145). 
im Grab des Frankenkönigs Childerich (von 481) lag neben einem prunkvollen Langschwert auch ein Kurzschwert, ${ }^{15}$ ebenso im englischen Königsgrab von Sutton Hoo (um 625); ${ }^{16}$ um 730 gehörte Abt Wido von Saint-Wandrille «zu den weltlichen Klerikern und hatte immer jene Art Schwert um, die man semispatium nennt»; ${ }^{17}$ Karl der Große verlangte nicht vom Fußsoldaten, wohl aber vom cabalarius, daß er spatam et semispatium mitbringe; ${ }^{18}$ und noch um 964 durchbohrte Graf Wilhelm Taillefer von Angoulème mit dem Kurzschwert einem Normannenführer die Brust ${ }^{19}$ - was aber sichtlich schon als Ausnahme berichtet wird. Denn das Lexikon des Mittelalters schreibt vom Sachs (s.v.) wohl mit Bezug auf das Karolingerreich sogar: «Seit dem 8. Jh. verschwand er aus der Bewaffnung des Kriegers.» Wie dem auch sei, für das sich im 11. Jh. voll entwickelnde ständische Rittertum folgte, wie dann schon die ältesten erhaltenen Chansons de geste sattsam bezeugen, auf den Lanzenkampf, wenn nicht schon dieser die Entscheidung brachte, jeweils sofort der Kampf mit dem Langschwert als einzigem Schwert, ${ }^{20}$ dessen durchschnittliche Klingenlänge übrigens bis ins 13 . Jh. noch zunahm (bis auf $90 \mathrm{~cm}$ und mehr). Das Kurzschwert hatte keine Funktion mehr; vielmehr bestand jetzt das Non-plus-ultra eines siegreichen Kampfes - wenigstens in epischer Übertreibung - darin, mit einem gewaltigen Hieb des Langschwertes den Gegner vom Kopf abwärts und möglichst noch sein Pferd in zwei Teile zu zerspalten. ${ }^{21}$ Vorgeführt wird uns ein solcher Hieb erstmalig - wohl in der ersten Hälfte des 11. Jh. - im Haager Fragment. ${ }^{22}$ In der zweiten Hälfte des 11. Jh. dürfte demnach die Vorliebe für ein kurzes Schwert, wie sie damals in Ogiers Beinamen zum Ausdruck kommt, schon einen gewissen Eigensinn seines Trägers und zumindest unterschwellig auch den Gedanken an ein wildes und mutiges, aber wenig rittermäßiges Gerangel auf Kurzdistanz suggeriert haben, sozusagen das Bild eines Ogier «the Ripper». ${ }^{23}$

15 Périn / Kazanski (1997a, 178).

16 Laux $(1978,486)$.

17 Pertz $(1829,284$ s.) = Löwenfeld $(1886,34)$, jeweils cap. 11 = Lohier/Laporte $(1936,57)$, cap. 7.

18 MGH, Capit. reg. Franc. I 168 nr. 75, a. 804-811.

19 Ademar von Chabannes III, cap. 28.

20 Cf. unter anderem das Beispielmaterial bei Rychner $(1955,129)$.

21 R. Menéndez Pidal (1960, 376 ss.), wo de Riquers Hinweis in n. 1 auf das Wilhelmslied vv. 3303-3328 zu beziehen ist.

22 Abschnitt 21 der Suchierschen Einteilung. Cf. auch die vorige n.

23 Nach 1200 freilich war die Erinnerung an die einstige Beliebtheit der Kurzschwerter so völlig geschwunden, daß man jetzt für den Schwertnamen Corte ein ätiologisches Histörchen brauchte: demzufolge hatte der Schmied oder Karl der Große zur Probe des Schwertes damit einen Amboß, Stahl- oder Marmorblock gespalten und beim Herausziehen ein Stück von der Klinge abgebrochen (La Chevalerie Ogier de Danemarche, ed. Eusebi 1963, vv. 1657-1673 ed. 
Möglicherweise stand bei dieser Entwicklung zum ausschließlichen Gebrauch des Langschwertes der durchschnittliche Nordeuropäer (nicht der Führer mit seinem Prunkschwert) dem durchschnittlichen Westeuropäer zeitlich nach. ${ }^{24}$ Wenn Rollos Sohn Herzog Wilhelm Mitte des 10. Jh. den Beinamen «Langschwert» bekam, so doch wohl aus seiner Umgebung von den vielen, die noch kein Langschwert besaßen; das Herzoghaus kann auch in diesem Punkte wie sonst Schrittmacher der Französierung und «Verritterung» gewesen sein. Um 970 schreibt Widukind von Corvey (I 6), die Angli führten lange Messer ( kurze Schwerter) «nach der Weise des alten Volkes noch heutigentags», und im 11. Jh. glaubt der Lukan-Kommentator Arnulf von Orleans, die Saxones führten noch arma[...]brevia. ${ }^{25}$ Insofern kann der Beiname Spatacurta durch eine zeitweilige Ideenassoziation 'Kurzschwert > Germane' die Umformung Ogiers zum Daneis erleichtert haben. Doch wird man sich für diesen neuen Beinamen noch eine spezifischere Begründung wünschen (dazu s. unten IV).

\section{III}

Die Geschichte des 8. Jh. zeigt uns bekanntlich einen Audgar, der als Herzog in Pippins Diensten 753 und 760 jeweils am päpstlichen und am langobardischen Hof weilte, dann wiederum einen Audgar, der einer der mächtigsten Vasallen Karlmanns gewesen sein muß, da er Ende 771 beim Tode des erst zwanzigjährigen Königs dessen Kinder über die Alpen brachte und für sie am langobardischen wie am päpstlichen Hofe tätig wurde. Auch wenn Audgar bei seinen ersten Missionen auf den Langobardenkönig, bei seiner letzten hingegen auf den Papst Druck ausübte, haben aufgrund der Ähnlichkeit dieser Tätigkeiten die meisten Forscher mit Recht die Identität der beiden Audgar für sehr wahrscheinlich gehalten. ${ }^{26}$

Barrois 1842, vv. 1648-1663; Karlamagnús Saga, ed. Loth 1980, I, Fassung A cap. 41; Jean d'Outremeuse, ed. Goosse 1965, 50 s., f. 337r und v der Hs.).

24 Cf. die Daten, die David Gale einerseits $(1989,71)$ für den Kontinent, andererseits $(78$ s.) für die Wikinger angibt; zu letzteren stimmt auch der angelsächsische Befund bei Lang/Ager (1989, 113 s.).

25 Ed. Marti (1958, zu Lukan 6.259).

26 In den letzten 130 Jahren hat im wesentlichen nur Voretzsch (1891, 17 s.) die Identität der beiden Audgar bezweifelt mit dem Argument, der ältere sei gegen die Langobarden für den Papst, der jüngere mit den Langobarden gegen den Papst aufgetreten - als ob nicht gerade die neue Politik Karlmanns und seiner Mutter Berta nach 768 diese Wendung Audgars voll erklärte! Mit guten Gründen widersprachen ihm u. a. Riezler (1892, 748 s.); Chaume (1922, 278): «l'importance du rôle de celui-ci auprès des fils de Carloman, qu'il veut faire couronner par le pape, ne s'explique vraiment que si l'on reconnaît en lui un diplomate de profession, très 
In den allgemein bekannten Dokumenten versteckt sich jedoch noch ein Argument, das die Personengleichheit fast zur Gewißheit erhebt.

Ein Großer Pippins namens Audgar wird für uns erstmalig sichtbar im Königsdiplom ${ }^{27}$ vom 1. März 752, demzufolge Fulrad, Abt des im Pariser Gau gelegenen Klosters St. Denis, die Villen Avezé im Gau Le Mans und Civry-laForêt bei Mantes im Madriegau erstreitet. Die Beisitzer des Königsgerichtes sind hier Milo, Rotgarius, Cheimgaudus (wofür wohl Chelmgaudus zu lesen ist), Crothardus, Gerichardus, Autgarius und Wibertus comes palatii. Nun wirkt der Pfalzgraf an allen solchen Urteilen als Verfahrensspezialist mit; im übrigen wissen wir: daß der Graf von Paris damals Gerhard heißt; daß im 8./9. Jh. lange ein Grafengeschlecht mit den Leitnamen Helmgauz und Gauzhelm die Grafschaft Meaux innehat; daß zwischen etwa 730 und 900 in Le Mans Grafen namens Rotgarius belegt sind; daß schließlich der Name Milo im 8. Jh. charakteristisch ist für die Familie der Widonen, die zumindest von 799 bis 852 Markgrafen- und Grafenämter längst der Grenze zur Bretagne innehaben. ${ }^{28}$ Insgesamt setzt sich also das Königsgericht hier wohl aus geographisch benachbarten, deshalb als sachverständig angesehenen Grafen zusammen; wir dürfen somit eine ähnliche Lokalisierung für Audgar erwarten. ${ }^{29}$

informé des choses d'Italie, et disposant déjà d'une certaine influence à Rome»; vor allem Lejeune (1948, 43 ss.). In Voretzsch' Denkgebäude bleibt übrigens sein Zweifel an der Identität «beider» Audgar ganz funktionslos und ist wohl nur als prinzipielle Gebärde einer Gewissenhaftigkeit zu deuten, die den Autor nichts kostet.

27 Mühlbacher (1906, 3 s., Nr. 1); cf. Lejeune (wie vorige n.).

28 Über den Grafen Gerhard I. von Paris, Großvater des Grafen Gerhard II. von Paris-Vienne (-«Roussillon»), berichtet ausführlich Louis (1946 passim). Zu den Helmgauz cf. Werner (1965, 142 n. 28, mit Verweis auf Chaume); zu den Rotgar Werner (ebd. 141 s. und 1958, 279-283). Die Belehnung eines Rotgar mit Limoges im Jahre 778 kann hier außer Betracht bleiben, da damals Karl erstmalig Franken seiner Umgebung nach Aquitanien verpflanzte. Zu den Milo-Wido existiert eine umfangreiche Literatur; cf. die bei Werner (1958, 270 n. 63) genannten Arbeiten sowie Schreibmüller (1952, 174-233) und Ewig (1954 passim). Diese Hinweise erstreben keine Vollständigkeit, sondern sollen nur eine Möglichkeit der schnellen Orientierung aufzeigen. Andererseits ist zuzugeben, daß sich m.W. Rothard als Grafenname bisher nur im lothringischelsässisch-alemannischen Raum hat nachweisen lassen.

29 Am 8. 7. 753 prozessiert Fulrad wieder vor dem Königsgericht, diesmal g e g en den Grafen Gerhard um die Pariser Marktzölle, also in einer für sein Kloster weit wichtigeren Sache, s. Mühlbacher (1906, 9-11, Nr. 6). Wiederum sind Milo, Helmegaudus, Chrothardus und Pfalzgraf Wicbertus anwesend, dazu elf weitere (worunter ein Raucho und ein Gisleharius); es fehlen also nur Rotgarius und Autgarius - und die Abwesenheit des letzteren ist insofern nicht erstaunlich, als er um den 1.10. bereits als Pippins Gesandter in Rom gewesen zu sein scheint (Oelsner 1871, 171 n. 3), sich also im Juli möglicherweise auf die Gesandtschaft vorbereitete oder gar schon im Aufbruch war. Und wenn Fulrad am 30.10.759 vor Wido, Raulco, Milo, Helmgaudus, Rothardus, Gisleharius und Pfalzgraf Wicbertus abermals gegen Graf Gerhard prozessiert (Mühlbacher 1906, 17 s., Nr. 12), scheint Audgar schon auf seiner zweiten Fahrt zum 
Im Dezember 771, höchstens vier Tage vor seinem Tod und schon an seinem Sterbeort, der Pfalz Samoussy, überantwortet nun König Karlmann dem Abt Fulrad von St. Denis die Villen Faverolles bei Nogent-le-Roi im Madriegau und Néron im Gau Chartres, die ihm einst sein Vater Pippin mit dem Auftrag übergeben hatte, sie an St. Denis weiterzuschenken, die aber bis jetzt im Besitze seines Vasallen Audegarius verblieben waren. ${ }^{30}$ Der Große Pippins und der namengleiche Vasall Karlmanns sind also nicht nur im Bedarfsfall Spezialisten für die Italienpolitik, sondern sie sind normalerweise von Amts wegen im selben Gebiet westlich Paris tätig. Mehr noch: dieses Gebiet bildet während der Reichsteilung, als bereits starke Spannungen zwischen Karl und Karlmann bestehen, den Vorposten von Karlmanns Reich gegenüber dem seines Bruders. ${ }^{31}$

Man vergleiche nun, was meines Wissens noch nie geschehen ist, diese Zeugnisse mit den berühmten Versen 4402-4411 der Chevalerie Ogier (ed. Eusebi; ed. Barrois 4420-4429):

\author{
[...] Puis m'a fait Kalles mult pener et cachier, \\ A Garlandon me vint il asegier, \\ Il et Callot que je n'ai gaires chier. \\ J'en afuï a cest roi Desïer, \\ Passai Mongieu por ma vie alonger; \\ S'en amenai Loüi et Loihier, \\ Ces .II. enfans petis a alaitier, \\ Qu'il voloit faire ocire e detrancher: \\ A Pentecoste les ferons chevaliers; \\ Encor volront vestre roi gerroier.
}

Ph. Aug. Becker (1940, 82) wollte bekanntlich diese Stelle durch die Behauptung banalisieren, es müsse sich um Ogiers, nicht um Karlmanns Kinder han-

\footnotetext{
Langobardenhof und von da nach Rom zu sein, wo Papst Paul I. seine Anwesenheit vor April 760 bezeugt. Von Graf Raucho wissen wir, daß er 766 Staatsgut in Essonnes bei Paris zu Lehen hatte, also offenbar eine benachbarte Grafschaft verwaltete.

30 Mühlbacher (1906, Nr. 53). - Voretzsch $(1891,18)$ vermutete zwar, der hier genannte Audegar sei bereits verstorben; allein Lejeune (1948, 76 n. 2) entgegnet mit Recht, daß die Urkunde gerade nicht von einem quondam Audegarius spreche. Überdies heißt es den Zufall strapazieren, wenn man annimmt, dieser Audegar sei einige Tage vor Ausstellung der Urkunde, der König selbst unmittelbar d a n a ch gestorben.

31 Für die Zeit der Reichsteilung (768-771) weist Lejeune (1948, 78 n. 3) mit Recht auf die Vita Karoli hin: multis ex parte Karlomanni societatem separare molientibus, adeo ut quidam eos etiam bello committere sint meditati - und wen sollen wir zu den quidam zählen, wenn nicht Audgar aufgrund seiner Handlungsweise unmittelbar nach Karlmanns Tod und, wie wir jetzt sehen, aufgrund seiner Funktionen im weitest vorgeschobenen Teil von Karlmanns Reich gegenüber dem seines Bruders Karl?
} 
deln, «denn diese wären bei der Flucht keine Säuglinge mehr gewesen». Aber die Kinder des erst zwanzigjährigen Königs standen notwendigerweise noch praktisch im Säuglingsalter, und Ludwig und Lothar sind nun einmal Karolingernamen; man sieht nicht, weshalb der Dichter Söhne Ogiers so genannt haben sollte. Die Stelle darf also sehr wohl als Relikt einer älteren Fassung gelten; damit aber wird auch das rätselhafte Garlandon interessant. Nun scheint es zwar in Frankreich keinen Ort dieses Namens zu geben, ${ }^{32}$ aber die Handschrift M nimmt gegen Ende der Chevalerie das Motiv noch einmal auf, indem sie Karl sagen läßt:

Je li rent chi l'onneur de Gaillardon

Dont le getai a tort par mesprison. ${ }^{33}$

Und diese Namensform ist die richtige. Denn das heutige Gallardon bei Maintenon heißt in älterer Zeit gelegentlich auch Gaillardon; es liegt gerade noch im Gau Chartres, wenige Kilometer von der Südspitze des Madriegaues entfernt; schließlich ist es schon im 11. Jh. als stark befestigt belegt. ${ }^{34}$ Wenn wir nicht vor dieser Stelle der Chevalerie schlechthin kapitulieren und eine willkürliche Lautfolge als Poesie ausgeben wollen, so bleibt nichts übrig, als eine ununterbrochene Tradition anzunehmen. Selbst wenn die Befestigung von Gallardon nicht auf das 8. Jh. zurückgeht, ${ }^{35}$ konnte sich eine in der Gegend weiterlebende Erinnerung an Audgar nach der Errichtung des stattlichen Donjons leicht auf diesen konzentrieren.

32 Wohl gibt es im 11. und 12. Jh. eine Familie de Garlande, die sich nach einem Weiler im Kanton Lagny (Seine-et-Marne) benennt, in Tournan und Livri in der Brie größere Besitzungen hat und durch die Gunst Philipps I. und noch Ludwigs VI. zeitweilig Hofämter und einen Bischofssitz innehat. Doch weder die Familie noch der Weiler tragen in ihrem Namen je das Suffix -on (Fliche 1912, Register unter Anseau, Etienne, Garlande; Luchaire 1890, XXXV; Waquet 1929, 41 n. 5; Stein 1954, s. v. Garlande.) Der Name Garlande reicht also eindeutig zur Erklärung der Chevalerie nicht aus; andererseits liegt er nahe genug, um als eine Art lectio facilior die Fehllesung Garlandon heraufbeschworen zu haben.

33 Ed. Eusebi, nota zu v. 4403; ed. Barrois, LVIII.

34 Merlet (1861, s. v. Gallardon); Spruner/Menke (1880, Karten 30 und 51).

35 Laut Lemarignier (1945, 69 s.) hat der Vizegraf Geoffroi von Châteaudun kurz vor 1025 die Burg Gallardon gebaut, doch läßt König Robert der Fromme sie 1025 auf Bitten des Bischofs Fulbert von Chartres schleifen und übergibt die Örtlichkeit dann einem gewissen Aubert le Riche zu Lehen. Aus solchen Angaben läßt sich jedoch im Mittelalter nie verläßlich schließen, daß sich nicht ebendort schon vorher gewisse Befestigungen oder deren Ruinen befanden; cf. die ganz parallele Entscheidung Longnons, später Lots zu Gouy-en-Arrouaise (Lot 1958, 51 mit n. 2). Zudem kann sogar die Erinnerung an die Schleifung von 1025 über das Alter der zerstörten Befestigung umso vagere und damit romantischere Vorstellungen haben aufkommen lassen. 
Hier haben wir also anfangs vielleicht wirklich eine légende locale, ${ }^{36}$ aber sie blüht nicht dort, wo wir sie vermutet hätten: in Meaux oder in Italien. Und wenn sie für uns in der Chevalerie des Raimbert von Paris sichtbar wird, ist sie schon eingemündet in den Strom einer viel breiteren Ogiertradition.

\section{IV}

Ogiers Beiname le Danois oder de Denemarche (Danemarche) ist bekanntlich bis auf den heutigen Tag nicht überzeugend gedeutet worden.

Leibniz sah darin eine Art Ehrentitel, und zwar letztlich ein mißverstandenes deutsches degen 'Degen, Held'. ${ }^{37}$ Diese Hypothese bedarf wegen ihrer extremen Willkür wohl heute keiner Widerlegung mehr.

Paulin Paris ${ }^{38}$ wollte von einem Ausdruck wie sponsor daciae ausgehen, worin dacia ursprünglich 'Steuer, Tribut' geheißen habe, dann aber als der Ländername 'Dakien' verkannt worden sei, den das Mittelalter bekanntlich seit dem frühen 11. Jh. fälschlich mit 'Dänemark' gleichsetzte. Aber erstens ist dacia weit davon entfernt, der Normalausdruck für 'Tribut' zu sein. ${ }^{39}$ Zweitens scheint mir die Erklärung eine petitio principii zu enthalten. Mit einem Tribut hat der epische Ogier nur insofern zu tun, als er in seiner Jugend Geisel für den dänischen Tribut an Karl ist. Setzt man dieses Motiv als gegeben voraus, so taucht mit dem Begriff 'Tribut' zugleich schon die dänische Herkunft auf, bedarf also nicht mehr der Herleitung über das Mißverständnis; postuliert man hingegen eine Vorstufe ohne den Begriff 'Dänemark', so verschwindet auch das erklärende Moment des Tributes.

Barrois (1842, Iss.) bemerkte, daß in der Handschrift B der Chevalerie Ogier der Held ein einziges Mal (v. 1344 ed. Barrois, v. 1355 ed. Eusebi) l'Ardenois statt le Danois genannt wird, und baute darauf seine Theorie, daß Danois ein verkanntes Ardenois sei. Aber erstens bedürfte eine Lokalisierung Ogiers in den Ardennen ihrerseits einer Erklärung, die kaum einfacher ausfallen dürfte als die

36 Einen sympathischen Versuch, im traditionalistischen Sinne sogar über R. Lejeune hinauszugehen und dabei Ogier im Raum um Laon festzumachen, unternimmt S. Martinet (1991, 291300). Leider fließt manches faktisch Unsichere, speziell zur Genealogie des historischen Audgarius, ein; vor allem aber fehlt jede Erwähnung entgegenstehender Forschungsmeinungen. 37 Leibniz, ed. Pertz (1843, 81-85).

38 P. Paris, in: Histoire littéraire de la France, XX, Paris 1842, 688-694.

39 Cf. dazu Du Cange, der das seltene datia/dacia (anscheinend eine Kreuzung zwischen data und datio/dacio) unter data 1) einreiht und nur Belege aus Italien und Österreich, und zwar aus der Zeit nach 1100, kennt. 
für Dänemark. ${ }^{40}$ Zweitens werden die Begriffe ‘Ardennen' und 'aus den Ardennen stammend' sonst in der altfranzösischen Epik - z. B. bei der Person des Thierry d'Ardenne - fast immer ${ }^{41}$ störungslos tradiert; weshalb sollte sich gerade bei Ogier ein so katastrophales Mißverständnis ungestört breitmachen können? So hat der neue Herausgeber Eusebi zweifellos recht, wenn er die auch in B vereinzelt bleibende Lesart in den Apparat verweist und offensichtlich einer momentanen Unaufmerksamkeit des Kopisten anlastet.

Gaston Paris (1882, 616 n. 3) fragt sich, ob der historische Audgar nicht auch Markgraf an der Dänengrenze hat sein können. Aber bevor Audgar im Dezember 771 das Frankenreich verließ, konnte von der Errichtung einer solchen Mark nicht die Rede sein, weil Sachsen noch selbständig war; und wenn Karl 773/4 Audgar auch nicht an Leib und Leben strafte, so hat er ihn doch nach dem Zeugnis der Chronik von Moissac ${ }^{42}$ «ins Exil gestoßen», womit in der Sprache der Zeit die Zwangseinweisung in ein Kloster, nicht aber ein Militärkommando, auch nicht in Grenzbezirken, gemeint sein kann. In diesem Zusammenhang taucht allerdings in der Romanistik gelegentlich, so noch bei Paul Aebischer, ein gewisses Chronicon S. Martini Coloniensis ${ }^{43}$ auf, demzufolge dieses Kölner Kloster kurz nach 778 per Olgerum Daniae ducem wiederaufgebaut worden sei; da das Chronicon im Jahre 1021 abbricht, läge an sich die Vermutung nahe, es könne um diese Zeit geschrieben sein und damit das erste Zeugnis für eine Verbindung zwischen Ogier und Dänemark darstellen. Demgegenüber ist darauf hinzuweisen, daß schon 1900 Otto Oppermann den durchschlagenden Nachweis erbracht hat, daß das Chronicon im 18. Jh. von einem Mönch des Klosters St. Martin namens Olivier Légipont gefälscht wurde. ${ }^{44}$ Die Vorstellung, St. Martin sei von Ogier von Dänemark erbaut, ist zwar keine freie Erfindung Légiponts, läßt sich aber, wie Oppermann eindeutig gezeigt hat, nur bis ins Jahr 1551 zurückverfolgen und ist damit für die Romanistik wertlos.

40 Nicht ausreichend, weil auf eine zu späte Zeit bezüglich oder aber inhaltlich zu unsicher, scheint mir in dieser Hinsicht alles, was Lejeune (1948, vor allem 98 ss., 105 ss., 167-184), über Ogiers Beziehungen zum heutigen Belgien vorbringt; es ist nur folgerichtig, wenn auch Lejeune nach einigem Zögern die Erklärung von Barrois ablehnt (181 ss.).

41 Langlois (1904, s.v.) verzeichnet, soweit ich sehe, nur ein einmaliges Tierri le Danois, Saisnes I 73, wo aber als Variante auch das übliche l'Ardenois belegt ist; wie man sieht, ist der Irrtum möglich, bleibt aber isoliert und damit praktisch folgenlos. Ähnliches wäre für Ogier zu erwarten, wenn die Entwicklung hier parallel verlaufen wäre.

42 MGH, Scriptores 1.295.

43 Aebischer (1969, 826); das Chronicon ist ediert von Pertz, MGH, Scriptores 2.214.

44 Oppermann (1900 passim). Schon Pertz hatte in seiner Edition dem Schreiber vorsichtigerweise vage eine recentior manus bescheinigt, und Wattenbach hatte die Quelle «nicht vor Ausgang des 13. Jh.» angesetzt; s. Togeby $(1969,239)$ und Voretzsch $(1891,22-25)$. 
Carl Voretzsch (1891, 79 ss.) wiederum glaubte, die Einleitung der Chevalerie Ogier sei dem Aspremont nachgebildet. Da dort Roland zu Anfang der Handlung in Laon eingesperrt erscheint, habe auch Ogier anfangs eingesperrt sein müssen; so habe man willkürlich Geiselschaft und dänische Herkunft Ogiers erfunden. Wie man sieht, handelt es sich hier eigentlich nicht um eine Erklärung, sondern um den Verzicht darauf; außerdem liegt die gewagte Voraussetzung zugrunde, schon vor dem Oxforder Roland, der ja die dänische Herkunft kennt, habe es ein volles Aspremont-Epos gegeben.

Der Genealogist J. Depoin (1906 passim), der auch sonst durch abenteuerliche Vermutungen hervortrat, fand in der Chronique des évêques de Tongres aus dem 15. Jh. die Bezeichnung Ogerus dux de Dammarchia und glaubte, in dieser Variante für 'Dänemark' vielmehr den Namen der Stadt Dammartin-en-Goële erkennen zu sollen, die von Meaux nur etwa $20 \mathrm{~km}$ entfernt liegt und die laut Depoin «einst» Dammars oder Dammarche genannt worden sei. Aber da Dammartin ein einfaches Domnus (= Sanctus) Martinus ist und einem bekannten, im Mittelalter etymologisch voll durchschaubaren Typ angehört, ist die letztere, von Depoin nicht belegte Behauptung a priori äußerst unwahrscheinlich. Inzwischen ist das ausgezeichnete Dictionnaire topographique des Départements Seine-et-Marne (Stein 1954) erschienen: natürlich heißt Dammartin, seit 1080 häufig belegt, dort nur Dommus Martinus u. ä., nie ${ }^{\star}$ Dammars, ${ }^{\star}$ Dammarche oder ${ }^{*}$ Dammarchie. Leider hat Maurice Chaume ${ }^{45}$ die These von Depoin zunächst zögernd, dann als Faktum übernommen.

Einen anderen Weg der Erklärung wiederum beschritt F. Gabotto: ${ }^{46}$ er versuchte zunächst mit ganz ungenügenden Indizien wahrscheinlich zu machen, Audgar sei ein Sohn des Alemannenherzogs Gottfried II. († a. 744/45) und damit ein Bruder jenes letzten Alemannenherzogs Theudbald, der kurz darauf in einem der blutigsten Kriege des 8. Jh. gegen den Hausmeier Karlmann unterging. (In diesem Falle müßten Karlmanns Bruder Pippin und dessen Sohn Karlmann dem Audgar ein geradezu ungeheures Maß an Vertrauen entgegengebracht haben!) Dann aber sei die Erinnerung an den Alemannen Gottfried auf den Dänen Gottfried übertragen worden. Von der Unbeweisbarkeit solcher relativ komplizierten Annahmen abgesehen, ist es mißlich, die Erklärung des Beinamens nicht an die Gestalt des Sohnes, sondern an die weit blassere, wahrscheinlich sekundäre des Vaters anschließen zu wollen.

45 In seinem Aufsatz (1922, 282) spricht er von einer fort intéressante suggestion; in seinen Origines du duché de Bourgogne (1925, 79 n. 1), ist daraus ein Faktum geworden.

46 Gabotto (1916, 150-167). Unbrauchbar ist auch die kurz anklingende Hypothese (p. 163) von einem «Donaugau» oder einer «Donaumark», die unter diesen Namen nicht belegt sind. 
Ph. Aug. Becker $(1940,69)$ glaubte zur Erklärung des Namens beizutragen, indem er nachwies, daß Dänemark vom 9. bis zum 11. Jh. in Frankreich z. B. durch Einharts Vita Karoli oder durch das Wirken Knuts des Großen bekannt war. Aber zu erklären ist nicht, warum Dänemark bekannt war, sondern was es mit Ogier zu tun hat.

Die - allerdings zögernd vorgetragene - Hypothese von Romuald Bauerreiß (1946, 22-25), hinter Ogiers Herkunftsbezeichnung Dacia (wie sie der PseudoTurpin belegt) verberge sich das bayrische Dießen, scheint mir bei jedem ihrer Denkschritte gegen die Wahrscheinlichkeit oder gegen ein eindeutiges Faktum zu verstoßen: die Identität des historischen Franken Audgar mit dem Gründer von Tegernsee ist unbewiesen; dessen Zugehörigkeit zu der erst über zweihundert Jahre später auftauchenden Familie der Grafen Friedrich und Otto von Dießen-Sundergau wird von Bauerreiß mit extremer Willkür und ohne jede onomastische Absicherung postuliert; Dießen heißt sonst nirgends Dacia, und Dacia ist nicht die älteste belegte Form des Beinamens. Bauerreiß erweist sich übrigens als mit der einschlägigen Literatur ungenügend vertraut.

Während Leibniz und P. Paris einst vermuteten, ein Appellativum sei mit einem lautlich nahestehenden Völkernamen verwechselt worden, glauben R. Lejeune und wohl auch P. Le Gentil, ${ }^{47}$ der Völkername sei hier ursprünglich metaphorisch gemeint, dann wörtlich genommen worden: Danois heiße ursprünglich einfach barbare, guerrier, farouche. Auch diese Erklärung ist bedenklich vage, zumal Togeby darauf hinwies, daß Ogier schon in der ältesten Quelle, die überhaupt den Beinamen kennt, im Rolandslied, nicht nur le Daneis, sondern auch mehrfach de Denemarche (Danemarche) genannt wird.

Togeby ${ }^{48}$ seinerseits erinnerte daran, daß 788 ein Heerführer Karls namens Audacar die aus Ungarn gekommenen Avaren schlug, und da das spätere Ungarn ein Teil der einstigen Dacia sei, lasse sich der Beiname vielleicht von hier aus erklären. Demgegenüber ist zu betonen, daß Audacar nicht mit dem Namen Audgar, sondern mit dem etymologisch davon verschiedenen Namen Audwac(c)ar (Odoaker) identisch ist; ${ }^{49}$ daß Audacar seinen Sieg nicht in Ungarn,

47 Lejeune (1948, 92 ss.); Le Gentil (1957 passim); dazu Togeby (1969, 18 und 68). Noch vager bleibt Spore (1999 passim). Sein Nachweis, daß sich das Adjektiv Daneis um 1100 im französischen Bewußtsein noch auf ganz Skandinavien beziehen konnte, trägt zum Verständnis Ogiers oder seiner Vorgeschichte nichts bei. Der historische wie der legendäre Karl hatten immerhin Beziehungen zu Dänemark, nicht aber zu Norwegen oder Schweden.

48 Togeby (1969, 19). Er folgte dabei einer Anregung von N. Lukman; cf. Togeby (1966, 111). Etwas später sprach Lukman gegenüber Togeby aber eine andere Hypothese aus; s. weiter unten.

49 Die Namen sind richtig getrennt bei Förstemann (1900, 201 ss.), sowie im Ergänzungsband dazu von Kaufmann (1968, 46 und 373 s.). Für die Zeit vor 1100 sollten sie bis zum Beweis des Gegenteils als nicht identisch gelten, obwohl außer Togeby auch Historiker wie E. Zöllner, 
sondern an der Ybbs in Österreich errang; schließlich daß Ungarn, von Grenzgebieten abgesehen, keineswegs Teil der Dacia war, auch in karolingischer Zeit nicht so benannt wurde.

Wenigstens mit einem Satze wollen wir einer weiteren, immerhin möglichen Fehldeutung zuvorkommen: der Erzbischof Otgarius von Mainz taufte zwar 826 in der Person Haralds II., der sich dazu an den Hof Ludwigs des Frommen begeben hatte, erstmalig einen Dänenkönig; doch dieser Umstand reicht gewiß nicht aus, dem Bischof willkürlich den Beinamen 'der Däne' zuzusprechen und überdies anzunehmen, sein Andenken habe sich mit dem des älteren, ihm so unähnlichen Audgar vermischt.

Schließlich macht Togeby in seinem Buch über Ogier $(1969,19)$ ohne weiteren Zusammenhang noch die folgende Mitteilung: «M. N. Lukman m'a suggéré qu'on pourrait penser au viking danois Oscer (Asgeir). Mais il faut conclure qu'on ne saurait identifier Ogier le Danois de façon définitive avec aucun personnage historique.» Eine Fußnote verweist zu Oscer auf Jan de Vries, De Wikingen in de lage landen bij de zee, Haarlem 1923. Wie man sieht, glaubt Togeby selbst nicht an die ihm mündlich mitgeteilte Hypothese, hält es aber nicht für nötig, ein Gegenargument beizubringen.

Wenn wir in diesem letzten Fall unser Urteil einen Augenblick zurückstellen, dürfen wir sagen, daß die übrigen Hypothesen ${ }^{50}$ nahezu sicher verfehlt sind.

M. Mitterauer und K. F. Werner sie implizit gleichsetzen. Im 12. Jh. allerdings scheinen sie gelegentlich vermischt zu werden, so bei Eberhard von Fulda. Wenn die Chevalerie Ogier den Sohn des Helden Baudouin nennt, so ist der Dichter vielleicht durch die Namenfolge AudacerBalduinus in der Genealogie der Grafen von Flandern beeinflußt; cf. Lejeune $(1948,158)$ und Togeby $(1969,49)$ mit J. Dhondt (1940 passim).

50 Ich selbst habe eine Zeitlang die Möglichkeit erwogen, Ogier de Denemarche könne ein mißverstandenes Ogier de la Marche sein; faßt doch Eusebi in v. 8453 (= 8507 ed. Barrois) tant sist li rois au castel de la Marche diesen Begriff - m. E. allerdings ohne zwingenden Grund als Eigennamen auf und heißt doch Marchia im italienischen Mittelalter gelegentlich 'die Markgrafschaft Toskana', z. B. Donizo, Vita Mathildis, II 1264 (MGH, Scriptores 12.404) Marchia nolendo sibi paruit, atque volendo. Dagegen spricht jedoch, daß schon im Rolandslied auch die adjektivische Benennung le Daneis gut bezeugt ist, daß überhaupt der neue Beiname von Nordwestfrankreich auszugehen scheint und daß die Beauvais-Episode (s. unten) bei dieser Annahme ungedeutet bliebe; schließlich sind Hypothesen, die einen akustischen Irrtum voraussetzen, in der Philologie immer mißlich, wenn die angeblich ältere Form nicht direkt belegt ist. - Die Tatsache, daß gegen Ende des 10. Jh. die Annales Lobienses (MGH, Scriptores 2.195) Ogier den Titel marchio geben, scheint mir zur Lokalisierung seines Herrschaftsbereiches und zur Erklärung seines Beinamens nicht beizutragen, da gerade in dieser Zeit der Markgrafentitel extrem unsystematisch den Herzögen und mächtigeren Grafen beigelegt wird; reiches Material findet man z. B. bei Kienast 1968, 57-60, 61 (mit n. 27) - 63 (mit n. 29), 74, 94, 147, 167, 190, 200, 260, 279-281 usw. passim. Auch die Chevalerie Ogier verwendet gelegentlich für Ogier noch diesen Titel, vor allem im Reim (z. B. v. 6737 ed. Eusebi 6771 ed. Barrois), nennt 
Bei unserer eigenen Erklärung empfiehlt es sich, zunächst die frühesten Zeugnisse der Beinamen in ihrer geographischen Verteilung zu betrachten. Im 11. Jh. trägt Ogier für den Mönch von San Millán und für ein Publikum um Oulx den Beinamen Spata Curta; für den Autor der Conversio von Meaux heißt er Praeliator Fortis und Pugnator und ist im Frankenreich secundus a rege; der Fälscher von St. Yrieix schließlich betrachtet vielleicht Palatinus als Beinamen. Keine dieser Quellen weiß von einer dänischen Herkunft, und im peripheren Bayern schließt noch gegen 1160 die Erzählung des Metellus von Tegernsee eine solche eindeutig aus. Das Rolandslied kennt für Ogier zwar ebenfalls noch die Bezeichnung li puinneres (3033) < pugnator, ist aber zugleich für die neue Benennung li Daneis $(3033,3544,3546)$ bzw. de Denemarche / Danemarche $(749,3856,3937)$ nicht nur das älteste Zeugnis, sondern von nun an wegen seines Siegeszuges durch Europa auch ein wichtiges, vielleicht das wichtigste Ausstrahlungszentrum..$^{51}$

Dazu paßt gut eine andere Beobachtung. Aus den Forschungen von Rajna und Rosellini ${ }^{52}$ geht insgesamt hervor, daß italienische Urkundenschreiber allgemein Beinamen, also auch epische, großzügiger aufnehmen als ihre französischen Kollegen, offenbar weil Italien dank der schnelleren Entwicklung der Städte früher dem Zweinamensystem zustrebt. In Italien läßt sich nun ein Oger Danesis (Danesius) seit 1157 in Genua nachweisen; weitere Personen mit diesem Doppelnamen folgen kurz nach 1200 in Saluzzo und Alessandria. Ferner sind kurz vor 1168 bei Neapel zwei Personen namens Danese belegt, und in Piove taucht 1169 schon der Sohn eines Danisio auf; da in der Chevalerie Ogier der Titelheld sehr oft nicht mit seinem Namen, sondern schlechthin als le Danois, le bon Danois bezeichnet wird, sind auch diese Belege von Interesse. Insgesamt darf man aus ihnen schließen, daß die neue Bezeichnung in der ersten Hälfte

aber ebenso unsystematisch und vereinzelt auch etwa Hoel von Nantes oder Thierry l'Ardenois marchis.

51 Aus dem Rolandslied hat den Beinamen wohl der Pseudo-Turpin (cap. 11, 14, 27, 29): Otgerius rex Daciae; mittellat. Dacia ist seit etwa 1000 gut belegt für 'Dänemark'. Allerdings weiß der Pseudo-Turpin von ihm auch schon aus anderer Quelle, sagt er doch (cap. 11): De hoc canitur in cantilena usque in hodiernum diem quia innumera fecit prodigia. Setzt innumera nicht schon fast die Tatenfülle des Ogier der Chevalerie voraus? Daß der Pseudo-Turpin Ogier dann in Roncevaux umkommen läßt, besagt nichts, läßt er dort doch ganz unpassenderweise auch Naimes, Hernaut von Bellande, die Lothringerbrüder Garin und Begon, Aubri den Burgunder u. a. sterben - kurzum jeden Helden, den er zu Recht oder Unrecht der Karlszeit zurechnete. 52 Rajna (1889, 52 s. und 66 n. 1); Rosellini (1958, 260). 
des 12. Jh. in Italien bekannt geworden sein muß - durch das erhaltene Rolandslied oder parallel $\mathrm{zu}$ ihm.

Für die Zeit bis und um 1100 legt der Kontrast zwischen den Quellen von San Millán, Oulx, St. Yrieix und Meaux einerseits und dem irgendwo zwischen Paris, Dieppe und Le Mans entstandenen Rolandslied andererseits die Vermutung nahe, das neue Motiv könne etwa derselben Gegend entstammen wie das Rolandslied selbst. An Zufall wird man hier umso weniger denken, als ja im 11. Jh. die Normannenprinzessin Emma, Tochter Herzog Richards «des Alten», in zweiter Ehe dem größten aller Dänenkönige, Knut dem Großen, König von Dänemark, England und zeitweilig Norwegen, seine drei ihm nachfolgenden Söhne geboren hatte - da mußte den Normannen ein Hereinnehmen Dänemarks in die romanische Epik sozusagen prinzipiell willkommen sein. Von hier aus scheint mir dann die Erklärung leicht zu finden.

Bis zum Jahre 840 einschließlich hatten normannische Banden zwar schon mehrfach Küstengebiete des Karolingerreiches, vor allem Friesland und Aquitanien, heimgesucht, noch nie aber dessen zentrale Bereiche wie etwa das Seinebecken. ${ }^{53}$ Im Mai 841 erfolgte dann unter einem Oscheri dux der erste große Angriff auf Rouen und sein Hinterland. Die Annalen des Westreiches (Annales Bertiniani), zu dieser Zeit geführt von Prudentius, der aus dem ehemaligen Westgotenreich stammte, bald darauf Bischof von Troyes wurde und sich in seiner Darstellung ganz überwiegend auf die innerfränkischen Gegensätze konzentrierte, berichten über den Zug naturgemäß weniger detailliert als das Chronicon Fontanellense, die Fortsetzung (841-859) der Gesta abbatum Fontanellensium und wie diese der essentiell zeitgenössische Bericht eines Mönchs von Saint-Wandrille (Fontanella). Hier heißt es: ${ }^{54}$

53 Wenn wir uns auf den romanischen Teil des Frankenreiches beschränken, so ist aus älterer Zeit i. w. nur eine kleine Expedition von dreizehn Schiffen zu nennen, die gemäß den Reichsannalen 820 vergeblich in die Seinemündung einzudringen versuchte, dann die Bretagne umfuhr und bei Bouin einige Beute gemacht zu haben scheint, sowie Angriffe gegen das Inselkloster Noirmoutier, das daraufhin 835 von seinen Mönchen aufgegeben wurde. Wie man sieht, sind solche Unternehmungen nicht entfernt vergleichbar mit dem tiefen Einbruch einer großen Flotte in eines der Hauptflußsysteme Frankreichs und mit der Eroberung einer erzbischöflichen Metropole.

54 MGH, Scriptores 2.301s. Anders als Pertz (1829) haben die späteren Editoren der Gesta, Löwenfeld (1886) und Lohier/Laporte (1936), das Chronicon als selbständiges Werk angesehen und deshalb nicht aufgenommen (doch finden sich bei Lohier/Laporte p. XII, XV, XVI, XXIII alle Angaben zur handschriftlichen Überlieferung auch des Chronicons). Hingegen betrachtet Lot (1913, CXXIX) das Chronicon - unseres Erachtens zu Recht - als eine Fortsetzung der Gesta, und Lot und Halphen zitieren in ihrem grundlegenden Werk Le Règne de Charles le Chauve (1909), das Chronicon fast vierzigmal einfach als Bestandteil der Gesta. 
Anno dominicae incarnationis 841, indictione 4, quarto Idus Maii venerunt Nortmanni, Oscheri quoque dux. Pridie Idus Maii incensa est ab eis urbs Rotomagus; 17. Kal. Iunii regressi sunt a Rothomago; 9. Kal. Iunii Gemmeticum monasterium igne cremarunt; 8. Kal. Iunii redemptum est Fontinellense coenobium libris 6; 5. Kal. Iunii venerunt monachi de sancto Dionysio, redemeruntque captivos sexaginta octo libris viginti sex. Pridie Kal. Iunii pagani mare petierunt. Obviusque illis factus est Vulfardus regis homo cum populo; sed pagani minime ad pugnam se praeparaverunt [...]

Der Byzantinist Henri Grégoire hat bekanntlich in anderem Zusammenhang als théorie du premier choc die Erfahrung ausgesprochen, daß sich von mehreren kriegerischen Ereignissen der gleichen Art das erste wegen seiner schockartigen Wirkung der kollektiven Erfahrung am stärksten einprägt; wenn dieser Grundsatz hier zutrifft, hat Oscheri dux schon wegen dieses Zuges gute Aussichten, in die Sage einzugehen. Aber mehr noch: in den folgenden zehn Jahren suchten er und seine Scharen viele andere Gegenden Frankreichs heim, um schließlich 851, abermals im Seinebecken, die größten Verwüstungen seit Menschengedenken anzurichten. Wiederum berichtet der Fortsetzungsteil der Gesta von St. Wandrille ausführlicher als die Annalen des Prudentius:

Anno 851 [...] Eodem tempore classis Nortmannorum fluvium Sequanam ingressa est ipso die tertio Idus Octobris, duce Hoseri, qui aliquot ante annos Rothomagum urbem depopularat ac incendio cremarat, id est anno dominicae incarnationis 841, et per annos undecim multas regiones latrocinando occuparat. Inter quas et urbem Burdegalim munitissimam, caput regionis Novempopulanae, de qua tunc progressus fuerat [...] Primitus Fontinellam monasterium agressi, cuncta eius depopularunt; ad extremum etiam post dies ingressus sui Sequanam 89. ipso die 5. Idus Ianuarii ad solum usque cremaverunt, cum stetisset a primo aedificationis suae die ducentis octodecim annis, mense uno, et dies tredecim. Belloacus interea urbem cremarunt, et Flaviacum monasterium. De qua cum reverterentur, in loco nuncupato Wardera a Francis excepti, plurimi interfecti sunt, reliqui silvis se occuluerunt; sicque noctu aliqui ad naves reversi sunt. Fuerunt autem in Sequana a tertio Idus Octobris usque Nonis Iunii dies ducentos octoginta septem. Sicque onustis navibus ad Burdegalim reversi sunt. Testantur regiones Sequanae adiacentes, quia ex quo gentes esse coeperunt, numquam tale exterminium in his territoriis auditum est. Tanta enim egerunt, quanta nemo prudentium cronographorum enarrare sufficeret; idcirco multa reliqui, quia sub brevitate narrare disposui.

In der Forschung scheint Einigkeit darüber zu bestehen, daß sich hinter Oscheri/Hoseri der altnordische Name Ásgeir verbirgt, ${ }^{55}$ dem im Fränkischen strenggenommen die Form Ansger entspräche; doch wird auch in den folgenden Jahrhunderten altnordisches $A s$ - in der Normandie sehr oft durch Os- wiedergegeben, z. B. stets in so gängigen Namen wie Osbern und Osmund - sei es, daß

55 Zum Namen cf. Vogel (1906, 84 mit n. 2). Asgeir nennt ihn auch der als Nordist ausgewiesene Jan de Vries (1923 passim, s. Index). 
in der Sprache der normannischen Invasoren das $a$ dunkel klang, sei es, daß angelsächsische und sächsische Namensformen auf Os- schon als Präzedenzfälle wirkten. Das in unserem Falle resultierende ${ }^{\star}$ Osger mußte in romanischem Mund allmählich von dem nahe benachbarten Namen *Odger (> Ogier) absorbiert werden. Und da die skandinavischen Eindringlinge des 9. Jh. in den lateinischen Quellen ebenso gängig Dani wie Nortmanni heißen, mußte wohl aus dem «Normannen Oscheri dux» allmählich ein Ogier le duc, le Daneis werden, der zur Zeit eines Königs Karl [nämlich des Kahlen] mit seinen Scharen, alles verwüstend, durch Nordwestfrankreich zog, dabei speziell Beauvais zerstörte, schließlich aber das Land räumen mußte. Sein Beiname le Daneis verhinderte anfangs gewiß eine Verwechslung mit jenem anderen Ogier le duc, der etwa achtzig Jahre früher schließlich vor König Karl [dem Großen] aus der Gegend westlich von Paris und damit aus ganz Frankreich hatte weichen müssen. Aber in dem Maße, in dem die Normannen ein französischer Volksstamm wurden, konnte man sich auch vorstellen, daß ein «Däne» zum Vasallen des Frankenkönigs Karl geworden war, und damit verblaßte die Trennungslinie zwischen den beiden Ogier.

Man vergleiche nun in der Chevalerie Ogier die Beschreibung der Verwüstungszüge, die Ogier nach seinem Zerwürfnis mit Karl in Laon und vor seinem Rückzug aus Frankreich unternimmt (vv. 3354-3365 Eusebi, 3360-3371 Barrois):

Et li Danois li fist maint enconbrer:

Le roi ocist maint vallant chevalier.

Maint borgoi prist, maint rice prisoner,

Dont il avoit et argent et or mer.

En Biauvisis entrerent li forrer;

Bialvais briserent dusqu'aus murs du terrier, Dusqu'a Bialmont fisent tot gerillier.

Li rois le suet, vis quida erragier;

Tant per l'a fait fuïr et decacher,

Et qe diroie? ne puet durer Ogier:

Fuïr l'estuet et le resne laissier

Et le roialme Kallemaine vidier.

Auch hier wird der Angriff als ähnlich wild und zerstörerisch wie ein normannischer Beutezug geschildert, und ganz wie in der Gesta-Fortsetzung fällt ihm speziell Beauvais zum Opfer.

Zusammenfassend dürfen wir dann wohl feststellen, daß der mündliche Hinweis von N. Lukman, den Togeby in einen indifferenten Satz zusammengedrängt hat, im Kern richtig ist. Zwar ist weder Osger der Däne schlechthin zu «dem» Ogier le Danois der altfranzösischen Epik «geworden» noch haben sich notwendigerweise, wie man vor hundert Jahren in einem derartigen Falle eilfer- 
tig angenommen hätte, «Lieder» über ihn mit solchen über den anderen Ogier «vermischt»; wohl aber hat er dort, wo die Erinnerung an ihn fortlebte - nämlich bei den alteingesessenen Nordwestfranzosen und/oder bei den bald einwandernden und dann schnell romanisierungsbereiten Normannen - zur Sage seines Quasi-Namensvetters den Beinamen und das Motiv der Zerstörung von Beauvais beigetragen.

Übrigens scheint der Romanistik bisher nur ein unwahrscheinlicher Zufall diese Lösung vorenthalten $\mathrm{zu}$ haben. Im Jahre $1912 \mathrm{kam}$ nämlich ein gewisser Paul Gruger in seinem Guide de Normandie (aus der Reihe der Guides Joanne) auf die Idee, den historischen Normannenführer unter dem Namen Ogier le Danois vorzustellen: «Ce fut sous Charles le Chauve, petit-fils de Charlemagne, que les terribles pirates scandinaves, dits les Northmans ou Normands, commencèrent en France leurs incursions. Conduits par Ogier le Danois, ils remontèrent la Seine jusqu'à Rouen en l'an 841 [...]».

Ein Menschenalter später stieß bei ihrer bahnbrechenden Untersuchung über Ogier ${ }^{56}$ auch R. Lejeune auf diese Sätze und zitierte sie, mußte aber aus der Ausdrucksweise schließen, es gehe hier bereits um den Epenhelden und Gruger präsentiere seinen Lesern versehentlich irgendeine sekundäre Lokalsage als historische Wahrheit; sie ging deshalb der Spur ebensowenig nach wie später Togeby dem Hinweis Lukmans. Habent sua fata Autgarii!

Kann unsere Erklärung also keinen Anspruch auf unbedingte Originalität erheben, so dürfen wir uns mit dem Gedanken trösten, daß es in einer Wissenschaft, in der mehr als ein Dutzend Hypothesen nebeneinander stehen, eher nottut, einer davon zum Durchbruch zu verhelfen als eine neue aufzustellen.

\section{VI}

Aufgrund der dänischen Herkunft Ogiers mußte im Sinne des Enfances-Denkens bald nach dem Namen seines Vaters gefragt werden. Zur Zeit Karls des Großen war im Frankenreich nur ein Dänenkönig, und zwar in negativer Weise, allgemein bekannt geworden: in der späteren dänischen Tradition heißt er manch-

56 Lejeune (1948, 183 n. 3). Lejeune weist in diesem Zusammenhang sogar darauf hin, daß der Pseudo-Philomena kurz nach 1200 wenigstens streckenweise einen Augerius den Dänen von einem Augerius Herzog der Normandie trennt; cf. Togeby (1969, 43 s.). Vielleicht erklärt sich die Verdopplung daraus, daß der Autor den «bekannteren» Ogier von einem «normannischen» Ogier trennen wollte, ohne jedoch den Beinamen des ersteren als Produkt einer schon vollzogenen Vermischung zu erkennen. - Relativ nahe kam unserer Erklärung auch schon de Vries (1923, 126 s.). 


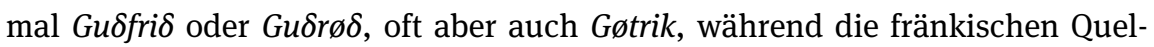
len, angeführt von den Reichsannalen, von Anfang an nur die erste dieser Varianten, latinisiert als Godofridus, kennen. ${ }^{57}$ Gottfried also - wie wir ihn nennen wollen ${ }^{58}$ - erscheint 804 mit seiner gesamten Reiterei und Flotte zu Demonstrationszwecken an der Schleswiger Grenze, kündigt sein Erscheinen in Karls Lager an, kommt dann aber auf Drängen seiner Großen nicht, sondern tauscht mit Karl nur eine ergebnislose Gesandtschaft aus. Im Jahre 808 muß der jüngere Karl Sachsen gegen ihn schützen. Im folgenden Jahre läßt er Karl dem Großen melden, er habe von dessen Zorn gegen ihn erfahren und wolle sich von allen Vorwürfen reinigen; er bittet zu diesem Zweck um ein Grenztreffen von Vertrauensleuten beider Seiten. Dieses zeitigt jedoch keinen dauernden Erfolg; denn kurz darauf läßt Karl aufgrund mancher Prahlereien und Gewalttaten Gottfrieds die Grenze befestigen. Nunmehr verwüstet 810 Gottfrieds Flotte im Handstreich Friesland. Karl läßt seinerseits eine Flotte ausrüsten und rückt mit dem Heer durch Sachsen vor. Gottfried prahlt, er werde Karl in offener Feldschlacht schlagen und mit gewaltiger Heeresmacht in Aachen erscheinen - da wird er von einem seiner Vasallen ermordet, und sein Neffe Hemming schließt mit Karl Frieden.

Wie man sieht, war Gottfried durchaus ein selbständiger König; doch mußten zumindest in breiten Schichten des Frankenreiches seine zeitweiligen Friedensangebote und Rechtfertigungen als stillschweigende Anerkennung der fränkischen Vormachtstellung, seine Drohungen dann als umso unverschämtere Rückfälle wirken. Darin entspricht er durchaus dem späteren Gaufroi der Epik.

Daran, daß - in fränkischem Munde - Godofridus einer der Leitnamen des dänischen Königshauses war, wurden die Franken im Laufe des 9. Jh. noch zumindest zweimal schmerzlich erinnert: ${ }^{59}$ ein jüngerer gleichnamiger Verwandter Gottfrieds wurde zwar 826 als Knabe in Mainz getauft, drangsalierte aber von 849 bis 855 Friesland und das dem König Karl [dem Kahlen] gehörige Flandern, einmal auch die Schelde- und die Seinemündung; ein dritter Gottfried und entfernter Verwandter der vorigen dehnte von 880 an seine Macht rheinaufwärts aus, forderte schließlich, dem Namen nach als kaiserlicher Vasall, von Karl [dem Dicken] Andernach und Koblenz, wurde dann aber von einem fränkischen Grafen ermordet. Schließlich tauchte 891 noch einmal kurz ein Norman-

57 Cf. Knudsen/Kristensen/Hornby (1936, 422 ss., 448 s.).

58 Zum Folgenden cf. z. B. Abel/Simson (1883, 307 s., 387 ss., 400 ss., 411 ss., 425 ss., 447).

$59 \mathrm{Zu}$ den jüngeren Gottfried cf. z. B. Dümmler (1887-88, I 343 s., 353 ss., 378; III 134, 157 ss., 201 ss., 206, 222, 237 ss., 350). 
nenführer dieses Namens auf; doch fehlen anscheinend Angaben über seine Familienzugehörigkeit.

In den folgenden Jahrhunderten ist der Name Godefridus/Godefroi im Osten des französischen Sprachgebietes (vor allem in Niederlothringen) und in einem gewissen Teil des Südwestens (etwa mit dem Zentrum Turenne) recht bekannt. In den meisten anderen Gegenden aber wird er an Häufigkeit um ein Vielfaches übertroffen von dem etymologisch nicht identischen, aber lautlich benachbarten Namen Gauzfridus, der im Westen und im Zentrum zu Jofrei/Jofroi/Gefrei, in weiten Gebieten der Normandie und in der Pikardie aber nur zu Gaufrei/Gaufroi/Gofrei/Gofroi wurde. Man kann nun feststellen, daß die beiden Namen manchmal für identisch gehalten wurden; beispielsweise macht der Pfaffe Konrad im deutschen Rolandslied (v. 129 u. ö.) aus Gefrei d'Anjou einen Gotefrit; Langlois verzeichnet unter seinen Godefroi zwei Personen, die in der Epik bzw. in der Wirklichkeit auch Jofroi heißen, ${ }^{60}$ und selbst in den Kartularen wird gelegentlich dieselbe Person mit beiden Namen bezeichnet. ${ }^{61}$ In den Gebieten des Nordwestens, wo nach unserer Meinung Ogier seinen Beinamen le Daneis bekommen hat, dürfen wir überwiegend mit der Form Gaufrei/Gaufroi rechnen. In der Tat heißt Ogiers Vater nun in der Chevalerie Ogier (und sonst in der altfranzösischen Epik seit dem späten 12. Jh.) Gaufrei/Gaufroi, so auch als Titelheld eines Spätepos, das ihm im 13. oder frühen 14. Jh. wahrscheinlich in der Pikar-

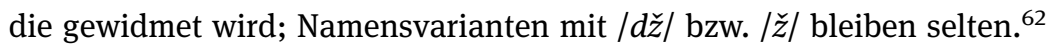

Die Identität des historischen Godofridus-Gøtrik mit dem epischen Gaufrei ist schon kurz nach 1266 von dem Verfasser einer Version der dänischen Annales Lundenses gesehen worden, dann im 15./16. Jh. von den dänischen Chroniken von Keiser Karl Magnus und Kong Olger Danske sowie von dem dänischen Humanisten Christiern Pedersen; ${ }^{63}$ in der philologischen Forschung wurde sie erkannt u. a. von Voretzsch, Togeby und Aebischer, ${ }^{64}$ doch immer ohne Untersuchung der hier durchaus wichtigen lautlichen Seite. Nur so konnte wohl Bédier (1929, 349) Gaufrei aus seiner berühmten Liste der historischen Personen ausschließen und damit stillschweigend seine Identität mit Godofridus leugnen - zu Unrecht, wie ich hoffe gezeigt zu haben.

60 Langlois (1904, s. v. Godefroi Nr. 1 und 29, letzterer von Lot richtig zu den Geoffroi de Lamballe der Wirklichkeit gestellt).

61 Beispielsweise heißt ein lokaler Großer a. 1095 im Kartular von Vierzon und im Livre d'Argent von Saumur Godefridus, in der Abschrift derselben Urkunde im Livre Noir von Saumur aber Gosfridus, in anderen Urkunden Goffredus, Gaufredus u. ä. (Devailly 1963, Register).

62 Langlois und Moisan können deshalb Gaufrei, Gefrei und Godefroi prinzipiell als drei selbständige Namen behandeln, zwischen denen es nur geringfügige Überschneidungen gibt.

63 Togeby (1969, 113 s., 227); Moisan (1986, vol. 1s. v. Gaufroi [1]).

64 Voretzsch (1891, 85); Togeby (1969, 49); Aebischer (1973, 15-21). 
Andererseits haben, von der Personengleichheit ausgehend, mehrere Forscher in älterer Zeit versucht, auch die Gestalt Ogiers ganz oder teilweise auf einen der Söhne Gottfrieds zurückzuführen, so im 16. Jh. Pedersen auf Olav, im 17. Jh. Bartolin mit Vorbehalten auf Helge, im 17. Jh. Mone auf Horich. ${ }^{65}$ Wir dürfen uns hier auf die Feststellung beschränken, daß nichts, was wir über irgendeinen der Gottfriedsöhne wissen, zu einer solchen Gleichsetzung einlädt.

Anders als bei Ogier selbst bleibt nach allem Vorangehenden allerdings unentscheidbar, ob Godofridus-Gaufrei auf gelehrtem oder auf volkstümlichem Wege in die altfranzösische Epik gelangt ist. Sicher kann ein Neugieriger, der wissen wollte, wie der Vater des Ogier de Danemarche hieß, den Namen Godofridus bei Einhart oder in den Reichsannalen aufgesucht und in der ihm geläufigen, vermeintlich etymologisch identischen Form Gaufrei sprechbar gemacht haben. Ebensowenig aber ist es auszuschließen, daß Gottfried in der mündlichen fränkisch-französischen Erinnerung als dänischer Komparse ohne nennenswerte narrative Umkleidung weiterlebte. Wichtig hingegen scheint mir für beide Hypothesen, daß Ogier zum Dänen wurde, ehe er zu Gaufrois Sohn wurde. ${ }^{66}$

\section{VII}

Im Vorhergehenden hoffe ich gezeigt zu haben, daß die scheinbar so komplexe Frage der Beinamen Spatacurta und le Danois eine rationelle Lösung findet, sobald man beiden Namen wenigstens umrißhaft eine historisch-geographische Dimension zuweist. Nun wird die Komplexität der Ogiertradition aber nicht nur durch die Beinamen, sondern mehr noch durch die weite geographische Streuung der Legende selbst und durch den Umstand bedingt, daß Ogier bald als Getreuer Karls, bald als Rebell gegen ihn auftritt. So sind die verschiedenen Versuche der Forschung, grundsätzlich zwei oder mehr Quellen der Ogiertradition zu unterscheiden, nicht etwa von dem Wunsch getragen, das eindeutig

65 Pedersen (ed. 1856); Bartolin (1677); Mone (1838); alle zitiert nach Voretzsch (1891, 2 und 7). Wir können hier von einer weiteren Schwäche der ersten beiden Thesen absehen, die darin besteht, daß strenggenommen von den fünf Gottfriedsöhnen nur einer, Horich, aus zeitgenössischen Zeugnissen namentlich bekannt ist; s. Vogel (1906, 405).

66 Selbst wenn sich hinter dem ganz isoliert stehenden Namen Grossaille (Rol. 1488, so nur 0) wider Erwarten ein ${ }^{*}$ Goffraille verbergen sollte, das der Dichter um der Assonanz und vielleicht um des pejorativen Beiklangs willen aus Goffrei gemacht hätte (insgesamt bezeugen Brigal, -gant, Haltilie, -toïe, Jurfaleu, -aret, Malpreis, -prose, Ormaleis, -leus doch wohl einen ziemlich ungenierten Umgang mit Heidennamen), so hätte er sich, nach dem Tenor der Stelle zu urteilen, Goffrei kaum schon als Ogiers Vater vorgestellt. 
sekundäre Motiv der dänischen Herkunft aus der Überlieferungsmasse auszusondern; vielmehr sollen sie durch Sondererklärungen für eines oder mehrere der frühen Elemente die geographische Vielfalt plausibler machen und für das Auftreten der gesamten Legende (oder speziell ihres «Rebellen»-Anteils) in Frankreich eine Spätdatierung ermöglichen.

Der Gedanke, den Ogier der Conversio von Meaux von der sonstigen Überlieferung zu trennen, klingt schon 1891 bei Voretzsch zaghaft an, wird dann von Bédier und Barry Cerf ausgebaut: ${ }^{67}$ in der klassischen Formulierung Bédiers handelt es sich hier um «un inconnu qui avait eu le mérite de donner quelques terres à l'abbaye de Saint-Faron et qui s'y était fait enterrer». Aber erstens müßte, wer das Motiv «erster Mann im Staate nach Karl» (secundus a rege bzw. in regni imperio et dominato [...] secundus) als nichtssagenden Topos behandeln will, parallele Beispiele für eine ähnlich groteske Vergrößerung der sozialen Statur eines mittleren Landadligen beibringen - ich kenne keine. Zweitens sagt die Conversio gerade $\mathrm{nich} \mathrm{t}$, daß Ogier der Abtei Ländereien schenkte, sondern daß er mit dem Pilgerstab in der Hand dorthin kam und kurz darauf König Karl dazu brachte, dem Kloster Schenkungen zu machen. Das paßt abermals nicht zu dem Bild eines mittleren Landadligen; bedenkt man jedoch, daß weithin im Mittelalter Adlige beim Eintritt in ein Kloster diesem, im wesentlichen als Grundlage ihres eigenen Unterhaltes, Ländereien schenkten, so erscheint es einleuchtend, daß Karl für den Unterhalt eines Verbannten dem betroffenen Kloster eine ähnliche Schenkung machte, schon damit die Mönche ihrer Bewachungsaufgabe auf würdige, aber auch wirksame Weise nachkamen. Und wenn das in beiden Fassungen der Conversio an Saint-Faron vergabte Klösterlein bei Vercelli, wie der Wortlaut der längeren Fassung beinahe mit Sicherheit besagt, einst Ogier gehörte, dann aber an den Fiskus fiel, so ist Bédiers Partie umso eindeutiger verloren; denn - so darf man Ferdinand Lots ${ }^{68}$ Einwand paraphrasieren - ein champagnischer Landadliger besitzt weder «zufälligerweise» ein Kloster in Italien, noch fällt dieses dann «zufälligerweise» dem Fiskus anheim. Das italienische Element im Leben des «zweiten» Ogier strapaziert also den Zufall zu sehr, um sich noch von der Biographie des «großen» Ogier trennen zu lassen.

67 Bédier (1926, 308-310, das folgende Zitat 310); Cerf (1910 passim). - Die beiden Fassungen der Conversio sind ediert von Krusch, MGH, Scriptores rerum merovingicarum 5.203-206, und zwar, wie in den Handschriften, als Anhang zur ebenfalls aus Meaux stammenden Vita Faronis.

68 Lot (1940, Wiederabdruck 1958, 285 n. 4 und 288 s.). - Für die obige Diskussion ist es fast gleichgültig, ob man mit Krusch (wie vorige n., 5.179) die kürzere oder mit Lot (284 n. 4) die längere Fassung der Conversio für die ursprüngliche hält, da gerade die längere Fassung auch laut Krusch op. cit. 178 in einer Hs. schon des 11. Jh. vorliegt. 
Barry Cerfs Annahme schließlich, ein Rotgarius aus der Zeit Lothars sei durch eine Verwechslung zu einem Othgerius aus der Zeit Karls geworden, muß man mit Ferdinand Lot $(1958,292)$ als besonders mißlich deshalb bezeichnen, weil gerade dieselben Schreiber beide Personen mühelos trennen. ${ }^{69}$

Was gegen diese Hypothesen einzuwenden ist, gilt a fortiori gegen die noch stärkeren Atomisierungsversuche Ph. Aug. Beckers (1940, 74-79): seine Annahme, erst das 13. Jh., und zwar wahrscheinlich der Dichter der Chevalerie selbst, habe die Legende von Otker von Tegernsee, dem historischen Autcharius, dem Otgerius miles von Meaux und dem dänischen Ogier des Rolandsliedes zu einer einheitlichen Gestalt verschmolzen, ist etwa so wahrscheinlich, wie es die Annahme wäre, ein heutiger Romandichter beobachte vier Personen, denen im wesentlichen nur der Familienname $\mathrm{X}$ gemeinsam ist, um daraus die Gestalt eines X-par-excellence zu gewinnen.

Als mit der Nota Emilianense ein etwa gleich altes und geographisch noch weiter abliegendes Zeugnis einer Ogierlegende auftauchte, konnte eine Isolierung der Conversio keine Spätdatierung und keine wesentliche geographische Konzentration der Ogierlegende mehr erbringen. Umso stärker geriet nun Ogiers «Doppelgesichtigkeit» ins Blickfeld, und zwar im selben Jahr 1969 bei so verschiedenen Forschern wie Paul Aebischer und Knud Togeby.

Aebischer (1969, 810-827) will konsequent den «treuen» Ogier der Nota Emilianense, der Conversio, der Fälschung von Saint-Yrieix und des Rolandsliedes von jenem «rebellischen» Ogier trennen, den er in der Geschichte der Jahre 771-773, bei dem Mönch von Sankt-Gallen, vielleicht in der Chronik von Moissac und den Annalen von Lobbes sowie schließlich in einem Ogierepos vorfindet, dessen verschiedene Fassungen für ihn durch Metellus von Tegernsee, die altnordische Karlamagnússaga, die dänische Karl Magnus Krønike und natürlich die Chevalerie vertreten sind. Diese Trennung kann aus zwei Gründen nicht befriedigen. Erstens bleibt die Hälfte des zu Erklärenden, nämlich die Gestalt des «treuen» Ogier, schlicht unerklärt. Denn der Hinweis auf die Historizität Gaufreis (art. cit. 821 s.) und der implizite Versuch, Ogiers Jugendgeschichte als zeitloses, will sagen, recht altes Ingrediens der altfranzösischen Epik darzustellen (art. cit. 825), ersetzen keine solche Erklärung.

Zweitens aber repräsentieren schon die Conversio und das Rolandslied nicht nur den «treuen» Ogier. Im Rolandslied fährt Ogier in einem Augenblick der

69 Versucht man Cerfs Grundgedanken - wie er es ansatzweise selbst (1910, 3 und 5), eindeutiger R. Lejeune $(1948,117 \mathrm{~s}$.) tat - durch die Zusatzannahme akzeptabler zu machen, Rotgarius sei in Saint-Faron nur dadurch zu Othgerius geworden, daß die Legende des epischen «Othgerius, des zweiten Mannes im Reich nach Karl», bereits auf ihn attrahierend wirkte, so wird damit die Conversio zu einem Zeugnis auch für den epischen Ogier; dieser Fall bedarf hier keiner weiteren Diskussion. 
Gefahr Karl an (3538 s.): «Ja Deu ne placet qu'el chef portez corone, / S’or n’i ferez pur venger vostre honte!» Läßt der Dichter hier nicht das Temperament des potentiellen Empörers durchbrechen ${ }^{70}$ Und in der Conversio deutet eben das Vercelli-Motiv auf die zeitweilige Rebellenexistenz - damit bricht die Unterscheidung zusammen. Aebischer verkennt entscheidend das hier vorliegende Wahrscheinlichkeitsproblem, wenn er glaubt, die beiden Traditionen berührten sich nur in einem Punkt, nämlich dem Namen Ogier, und wenn er von der Abtei bei Vercelli schreibt: «abbaye qu'il aura reçu de Désier, suppose un peu gratuitement Ferdinant Lot, et qui forcément lui aura été confisquée par Charlemagne, lequel la lui aura rendue au moment où il s'est fait moine. ${ }^{71}$ Vielmehr berühren sich der Ogier der Conversio und der des Jahres 774 darin, daß sie denselben Namen tragen, daß sie Zeitgenossen Karls des Großen sind, daß sie zunächst im Frankenreich eine der höchsten Stellungen gleich nach dem Königsrang bekleiden, daß sie dann aber in ein Kloster eintreten, zu dem sie vorher offensichtlich keine Beziehung unterhielten. Schon angesichts dieser Übereinstimmungen fällt die Unterscheidung beider schwer. Taucht nun in der Biographie des einen noch das Motiv eines Besitzes in Italien auf, und zwar mit großer Wahrscheinlichkeit eines von Karl zeitweilig konfiszierten Besitzes, so wird die Trennung extrem unwahrscheinlich, und genau das wollte der Fachhistoriker Lot in seiner etwas apodiktischen Kürze sagen.

Bei Togeby zeigt sich über Aebischer hinaus das Bestreben, den rebellischen Ogier in der Literatur als späte Schöpfung eines individuellen Dichters, nämlich des Verfassers der Chevalerie, darzustellen. ${ }^{72}$

Aber zwischen der ersten Quelle, die uns von Ogiers Rebellion und Unterwerfung berichtet, nämlich der Vita Hadriani (vor 800), und der Chevalerie (um 1200) liegen zumindest sieben Texte, die sich gerade mit dem Abgang Ogiers von der weltlichen Bühne befassen; jeder von ihnen bringt mindestens ein neues, meist legendäres Motiv, und immerhin die Mehrheit dieser Motive wird sich in der Chevalerie wiederfinden. Zwar sind sechs dieser sieben Texte der Romanistik prinzipiell bekannt, allein da ihr Zeugnis diffus präsentiert oder zerredet worden ist, können wir nicht umhin, sie kurz zu rekapitulieren.

70 So auch Ruggero M. Ruggieri $(1969,42)$.

71 Aebischer $(1969,817)$. Später sah Aebischer $(1973,30)$ hyperkritisch in der bloßen Tatsache, daß diese Abtei nicht näher zu identifizieren ist, einen Grund, an ihrer Existenz zu zweifeln, obwohl die Conversio einleuchtend genug sagt, daß ihre Unterordnung unter Saint-Faron de Meaux verloren ging, als Frankreich und Italien nicht mehr unter denselben Königen standen. Übrigens: selbst wenn die Angabe der Conversio erfunden wäre, würde sie zeigen, daß die Mönche ihren Ogier als begütert in Italien erscheinen lassen wollten - und schon das spräche für eine intendierte Identifizierung mit Audgar.

72 Togeby (1969, am klarsten 72 und 294). 
Die Vita Hadriani selbst hatte berichtet, Ogier habe sich aus dem belagerten Verona mit Karlmanns Witwe und Kindern propria voluntate dem benignissimo Carulo ergeben, der sie - in welcher Weise, wird nicht gesagt - «aufnahm» (eosque recipiens). ${ }^{73}$

1) Im Laufe des 9. Jh. weiß nun die Chronik von Moissac ${ }^{74} \mathrm{zu}$ berichten, Karl und eine Elitetruppe (legionem ex probatissimis pugnatoribus) hätten die langobardischen Paßbefestigungen bei den Klausen auf einem Bergpfad umgangen ${ }^{75}$ und anschließend die Langobarden mit Desiderius und Ogier in die Flucht geschlagen (Langobardos cum Desiderio rege eorum et Oggerio in fugam converterunt). Und vom Schicksal der Gefangenen heißt es: truso in exilium Desiderio rege et Oggerio, et uxore et filia (wo, wie der Zusammenhang zeigt, die Frau und die Tochter des Desiderius gemeint sind). Exilium heißt hier sprachlich, wie Bédier (1926, 309 n. 1) richtig erklärt, 'Gefängnis'; aber da wir von Desiderius und seiner Familie eindeutig wissen, daß sie den Rest ihrer Tage unter geistlicher Bewachung - nämlich hinter Klostermauern oder in der direkten Verantwortung eines Bischofs - verbrachten, darf man wahrscheinlich mit Ferdinand Lot (1958, 289 n. 1) auch das 'Gefängnis' des in ihrer Mitte genannten Ogier als Kloster oder (woran Lot nicht dachte, was aber nach Analogie des Desiderius ebenso möglich ist) als strenge bischöfliche Bewachung deuten. In ihrer Essenz werden die beiden neuen Motive - nämlich Ogiers Teilnahme an Kampfhandlungen samt seiner anschließenden Flucht sowie seine Einweisung in klösterliche bzw. bischöfliche Obhut - zu den Hauptthemen der späteren Ogierepik werden, und zwar einerseits in der Chevalerie, andererseits in der Moniage-Tradition.

2) Zwischen 883 und 887 erzählt uns der Mönch von St. Gallen ${ }^{76}$ die bekannte non-adhuc-Episode vom furchterregenden Aussehen des «eisernen Karl» und zeigt dabei Ogier nicht wie in der Geschichte mit Adelgis in Verona, sondern mit Desiderius in Pavia (lat. Ticinum) belagert. Der Motivkomplex OgierDesiderius-Pavia wird in der Chevalerie bleiben; nur erscheint dort Ogier im letzten Augenblick aus der Stadt ausgesperrt - damit die Handlung weitergehen kann. ${ }^{77}$

3) In der zweiten Hälfte des 10. Jh. gibt der Annalist von Lobbes ${ }^{78}$ Ogier den Titel marchio und nennt die Zahl der Söhne Karlmanns, nämlich zwei. Beide Elemente finden sich noch in der Chevalerie.

73 Liber Pontificalis, I 496; Bédier (1926, 197).

74 MGH, Scriptores 1.295.

75 In der Chronik der Novalese finden wir dann dieses Motiv stark legendär ausgestaltet (aber keineswegs frei erfunden!) wieder.

76 MGH, Scriptores 2.759 s.; Togeby (1969, 55 s.).

77 Verse 5831-5845 ed. Eusebi, 5858-5872 ed. Barrois.

78 MGH, Scriptores 2.195. 
4) Spätestens im dritten Viertel des 11. Jh. berichtet die Conversio in beiden Prosafassungen und in der Versifizierung durch Foulcoie, Ogiers unzertrennlicher Begleiter in seinen Kämpfen habe Benedictus geheißen, sei mit ihm Mönch in Meaux geworden und dort begraben - die Chevalerie wird alle diese Elemente aufnehmen. Nur wird sie, um Ogier noch mit Brabant und Hennegau belehnen zu können, erst den toten Ogier ins Kloster Saint-Faron de Meaux führen; skurrilerweise und offensichtlich als Relikt einer älteren Handlungsführung hat aber vorher sein Roß schon Jahre im Dienste dieses Klosters zugebracht, während Ogier selbst von Erzbischof Turpin in Reims gefangen gehalten wurde.

5) Um 1120-25 fälscht auf der Reichenau ein den Cluniazensern nahestehender Mönch u. a. für das Kloster Kempten Urkunden Karls und Hadrians, deren Grundgedanke es ist, Karl habe bei seinem österlichen Aufenthalt 774 in Rom den adligen bisherigen Laien Audogarius zum ersten Abt von Kempten eingesetzt. ${ }^{79}$ Diese lokale Seitenüberlieferung ist psychologisch dadurch von Interesse, daß sie mit derselben Leichtigkeit wie die Conversio die Rebellion des Helden verdrängt, sich vielmehr auf seinen folgenden Eintritt ins Kloster und die so erkaufte Versöhnung mit Karl beschränken will.

6) Als um 1160 Metellus von Tegernsee seine Quirinalia ${ }^{80}$ dichtet, stehen durch die Heirat Barbarossas seit einigen Jahren die deutschen Gebiete des Imperiums in engster Wechselbeziehung zu Burgund. Metellus berichtet nun, noch heute sängen die Burgunder von ihrem Herzog Ogier, und identifiziert diesen mit Otker, einem der beiden Brüder, die um 760 das Kloster Tegernsee gründeten. Dann erzählt er jene berühmte, tragisch ausgehende Schachspielepisode, die wir in der Chevalerie wiederfinden; nur macht er sie seinen Zwecken dienstbar, indem er sie als unmittelbare Voraussetzung für Ogiers Eintritt ins Kloster darstellt.

7) Alexander Neckam, der von 1180 bis 1186 in Paris lehrte, kommt, als er in seinem De naturis rerum (cap. 158) von berühmten Pferden handelt, auch auf Ogiers Pferd zu sprechen. Er erzählt, wie Ogier, schon Mönch in Meaux, noch einmal die in Frankreich einfallenden Sarazenen besiegen und dazu auch sein altes Pferd reaktivieren muß. Selbst wenn Neckam dies einer hagiographischen

79 Mühlbacher (1906, 296-300, Nr. 222 s.). Außer der dort angegebenen Literatur cf. Hirsch (1911 passim); Germania Pontificia, II $1.234 \mathrm{~s}$. Die ältere, möglicherweise aber auch schon unhistorische Tradition, die für uns Mitte des 11. Jh. bei Hermann von Reichenau (MGH, Scriptores 5.99) sichtbar wird, nennt als Gründer und ersten Abt von Kempten auch schon Audogarius, aber zu a. 752 und damit nicht in Zusammenhang mit Karl dem Großen und dessen Italienzug von a. 773/74. Der Fälscher zeigt dann durch die Umdatierung und das Hineinbringen von Karls Italienzug, daß er eine Legende kennt, wonach Karl auf seinem Italienzug Audgar ehrenhaft in ein Kloster einwies.

80 Peters (1913, speziell 66-68); Jacobsen (1965, speziell 207-208); Togeby (1969, 28 s.). 
Quelle entnommen haben sollte, ${ }^{81}$ beruht diese ihrerseits auf epischem Material. Denn hier wird ja der unhistorische Schlußteil der Chanson de geste sichtbar, nämlich dessen Zentralthema einer letzten kriegerischen Großtat Ogiers nach der Versöhnung mit dem Monarchen samt dem nostalgischen Nebenthema des alten Pferdes - auch wenn die erhaltene Chevalerie dann beide Themen etwas anders gestalten wird.

Wie man sieht, handeln alle diese Texte entweder ausdrücklich von einer schweren Krise zwischen Karl und Ogier vor dessen Eintritt ins Kloster, oder aber wir ertappen ihre Autoren - nämlich in Meaux und Kempten - dabei, wie sie die Krise kennen, aber verdrängen; sie bezeugen also eine Tendenz, von der frühen Doppelgesichtigkeit Ogiers nur die problemlose Hälfte wahrzunehmen. Im Zeitalter der Vorkreuzzüge und des ersten, überwältigend erfolgreichen Kreuzzuges dominiert offenbar aus ideologischen Gründen ein fast makelloses Karlsbild, und die Rebellentraditionen führen eine Zeitlang ein ziemlich bescheidenes Dasein; erst als im späteren 12. Jh. das westeuropäische Rittertum in seiner äußeren Expansion gegen den Islam schwere Rückschläge erleidet, zugleich aber im Innern vor der Expansion des Königtums zurückweichen muß, haben die Rebellenerzählungen ihre geschichtliche Stunde. ${ }^{82}$ Noch aufschlußreicher aber ist es, wie schon R. Lejeune und R. Louis ${ }^{83}$ gezeigt haben, die faktenfreudige Vita Hadriani mit Einhart und den fränkischen Annalen zu vergleichen, die - außer im peripheren Moissac und später im ottonischen Lobbes die Anhänger der Karlmannssöhne mit der Strafe der Anonymität belegen, obwohl Audgars Kampf nach seiner Motivation ein innerfränkischer und nur umständehalber ein antipäpstlicher Kampf war, also eher Gegenstand der fränkischen als der päpstlichen Geschichtsschreibung hätte sein sollen. Von einem Zufall auf fränkischer Seite kann keine Rede sein; vielmehr gesellen sich zu den obengenannten «Verdrängern» des 11. und 12. Jh. eindeutig die frühen «Verschweiger», die noch der Sprachregelung des Karolingerhofes unterworfen sind.

Wenn aber die Spuren des état latent so eindeutig sind, dürfen wir mit R. Louis feststellen: «Les critiques qui veulent voir dans l'Ogier fidèle du Roland d'Oxford le type primitif et dans l'Ogier rebelle de la Chevalerie un type dérivé, énoncent un paradoxe invraisemblable: comment admettre de sens rassis que l'Ogier historique, rebelle à Charlemagne, soit d'abord entré dans la légende sous les traits d'un fidèle pour se muer à nouveau en rebelle?» 84

81 So Bédier (1926, 323 s.).

82 Cf. allgemeiner dazu Bender (1967 passim).

83 Lejeune (1948 passim); Louis (1956, 405).

84 Louis $(1956,394)$, zitiert auch von Aebischer $(1969,825)$. 
Aber wieso kommt dann die doch recht eindeutige Erzähltradition der Krise zwischen Karl und Ogier dem Leser des Togebyschen Buches kaum zum Bewußtsein?

Erstens ordnet Togeby seine Untersuchung in anscheinend musterhafter Objektivität chronologisch an; doch tendenziös ist gerade die Vorentscheidung, die Darstellung erst mit der Zeit um 1060 zu beginnen. Dadurch lernt der Leser alle älteren Denkmäler in der Perspektive eines Rückblicks kennen und muß dazu neigen, sie als außerhalb des Hauptstranges der Argumentation stehend anzusehen.

Zweitens wird beim Vergleich der Erzählung des Mönchs von St. Gallen mit der Chevalerie das gemeinsame unhistorische Element Pavia für belanglos gehalten. ${ }^{85}$

Drittens findet der dänische Forscher zwar auf 280 Textseiten im allgemeinen Gelegenheit, jedes Zeugnis der Ogiertradition ausführlich zu beschreiben; allein um aus dem 9. und 10. Jh., also dem klassischen Streitgebiet der Vorepentheorien, die je drei Zeilen der Chronik von Moissac und der Annalen von Lobbes $\mathrm{zu}$ zitieren, fehlt der Raum. Togeby verweist global auf Voretzsch und Lejeune (nicht aber z. B. auf Louis). ${ }^{86}$

Viertens wird aus der Conversio zwar das Vercelli-Motiv als particulièrement problématique vorgestellt, aber fast ohne Untersuchung seiner Wahrscheinlichkeitsstruktur, so daß der Leser kaum ahnen kann, an welchem Kreuzweg der Forscher hier steht. ${ }^{87}$

Fünftens bleiben die Fälschungen für Kempten - und damit immerhin ein psychologisches Pendant zur Conversio - Togeby ebenso wie der übrigen Romanistik unbekannt.

Sechstens stellt sich bei der Schachspielepisode unabweislich die Frage, ob der Bayer Metellus sie aus einer Chanson de geste entlehnt hat oder umgekehrt. Metellus berichtet zwar in seiner Ode 11a, man singe in Burgund viel von Ogier, und weil er in seiner Klostertradition Otker als Zeitgenossen Pippins, in Burgund aber Ogier als Zeitgenossen Karls dargestellt findet, läßt er in dieser Ode

85 Togeby $(1969,55$ s.).

86 Ebd. 54 s.; Louis $(1956,405)$.

87 Togeby (1969, 21 und 59). - Stattdessen lenkt Togeby den Leser ab auf einen Seitenpfad: er verweist in der Nachfolge von Cerf (1910, 8 n. 18) darauf, daß in der Vita Faronis auch ein sanctus Autharius erwähnt wird, dont le nom a également pu être identifié avec une forme latine d'Ogier. Er sagt nicht, daß dieser Autharius im Zusammenhang der Vita eindeutig als Person des frühen 7. Jh. erkennbar ist und daß dies elben Schreiber diesen frühen Autharius mühelos von dem späteren Othgerius-Otgarius trennen; cf. Togeby $(1969,22)$ mit der Ed. Krusch. Chaume $(1969,78)$ identifiziert sogar die nur ähnlichen Namen Autharius und Autgarius und gelangt somit zu einer Ahnenreihe, die weder wahrscheinlich noch für uns von Interesse ist. 
den König vorsichtigerweise unbenannt; der Leser kan n ihn mit dem in Ode 11 genannten Pippin identifizieren, braucht dies aber keineswegs. Doch trotz solcher deutlicher Indizien für die Entlehnungsrichtung befindet Togeby $(1969,29)$ : «Mais l'auteur de la Chevalerie Ogier peut tout aussi bien avoir emprunté l'anecdote à Metellus.» Nun erscheint überdies eine eng verwandte Schachspielepisode im Renaut de Montauban, der laut Togeby (op. cit. 40) der Chevalerie vorangeht. Woher hat sie der Renaut? Wahrscheinlich, so antwortet Togeby (op. cit. 53), aus einer «source commune, par exemple Metellus». Die Frage, ob Metellus je außerhalb Bayerns rezipiert wurde, wird gar nicht erst gestellt; und die source commune darf offenbar alles sein - außer einer verlorenen Chevalerie Ogier.

Siebtens erkennt auch Togeby an, daß Ogiers Kindheitsgeschichte bekannt war, bevor die uns erhaltene Chevalerie gedichtet wurde (1969, 38, 47 s.; cf. 50). Nun enthält aber diese Kindheitsgeschichte in allen bekannten Fassungen das Thema der Rivalität, ja Feindschaft zwischen Ogier und dem Königssohn, das seinen Höhepunkt und damit seinen dramatischen Sinn erst in der Schachspielepisode des Hauptteils erreicht. Sollen wir annehmen, das Thema sei unabhängig zweimal ersonnen worden, nämlich von Metellus und von dem Dichter der selbständigen Enfances? Welchem Ende soll letzterer es zugeführt haben, wenn er die dramatische Weiterentwicklung nicht kannte, die vorher bei Metellus, nachher in der Chevalerie belegt ist? Oder ist auch er ein heimlicher MetellusLeser? Ist es überhaupt wahrscheinlich, daß ein Enfances-Epos einer Gestalt gewidmet wird, die noch in keinem anderen Epos Protagonist war?

\section{VIII}

Bleiben somit alle Versuche unbefriedigend, die Ogiertradition (abgesehen von dem Motiv der dänischen Herkunft) auf verschiedene Quellen zurückzuführen, so muß man sich fragen, ob diese Versuche nicht von falschen Voraussetzungen ausgehen, nämlich von einer Unterschätzung selbst des mittelalterlichen Geschichtsbewußtseins. Ist denn die Doppelgesichtigkeit Ogiers psychologisch unverständlich? Oder gar die Entwicklung der Rebellenfabel in sich? Was konnte denn eigentlich an Ogiers Schicksal im Bewußtsein der ersten nachfolgenden Generationen «relevant» sein? Was bewahrte ihn davor, schlechthin vergessen $\mathrm{zu}$ werden? Diese «Relevanzfrage» sollte bei aller Forschung zur Vorgeschichte der altfranzösischen Epik gestellt werden; denn vornehmlich um ihretwillen lohnt solche Forschung überhaupt.

In unserem Fall nun liegen die beiden entscheidenden Umstände zweifellos darin, daß Ogier s chrittweise in die völlige Vereinzelung geriet und daß 
ihm schließlich Karl in einem gewissen Sinne «verzieh». Er geriet in die Vereinzelung, indem er mehrfach vor die Alternative gestellt wurde, aufzugeben oder seine bisherige Haltung um eine Stufe - allmählich bis in die desmesure hinein - $\mathrm{m}$ zu verhärten. Im Jahre 771 bekleidete er einen der höchsten Ränge in demjenigen fränkischen Teilreich, dem die Zukunft zu gehören schien: Karlmann hatte zwei legitime Söhne, Karl trotz seines höheren Alters nur einen körperlich mißgestalteten von zweifelhafter Legitimität; Karlmanns Reich war räumlich kompakt, das seines Bruders monströs weitgestreckt und auf die Dauer kaum lebensfähig. Da verfiel Karlmann einer tödlichen Krankheit, doch so, daß er selbst noch Zeit für letztwillige Anordnungen und sein Bruder Karl schon Zeit für einen Aufmarsch an der Grenze fand. ${ }^{88}$ Es ist in dieser Situation $\mathrm{zu}$ vermuten, daß der todkranke Karlmann einen Großen seines Vertrauens zum Beschützer seiner Söhne einsetzte. Nun waren die Franken zwar aus ihrer nationalen Geschichte an Teilungen des Reiches und (vor 751) der Majordomuswürde gewöhnt. Doch gab es keine eindeutige Tradition in der Frage, ob hierbei auch Minderjährige ein Anrecht hatten; gegen ihre Berücksichtigung sprachen nicht nur die Erfahrungen nach dem Tode Pippins des Mittleren, sondern auch die Überlegung, daß konsequente Teilungen schließlich zur Zerstücklung des Reiches führen mußten. Im Prinzip durften in einer solchen Lage die Großen und das Volk innerhalb der Königs sippe ihren neuen Herrscher wählen, zumindest soweit sie sich nicht bei Lebzeiten des Vorgängers schon gebunden hatten. Beim Tode des erst zwanzigjährigen Karlmann hatten gewiß die meisten seiner Untertanen ein solches Gelöbnis noch nicht abgelegt, sich ihm vielleicht in den letzten Lebenstagen des Königs bewußt entzogen. Als sie sich nunmehr legitim für Karl entschieden, mußte ihnen die gegenteilige Haltung einer Minderheit um Audgar zwar politisch falsch, aber keineswegs moralisch unverständlich erscheinen, im Gegenteil. Audgars erste Entscheidung zog unmittelbar eine zweite nach sich. Wäre Karlmanns Familie im Frankenreich verblieben, so hätte Karl sie zweifellos zum Eintritt ins Kloster gezwungen; denn er konnte es sich nicht leisten, in weltlichem Stande zwei prinzipiell thronfähige Jungen heranwachsen zu lassen, die bei jeder Reichskrise selbst gegen ihren Willen zu Kristallisationszentren des Widerstandes geworden wären. So flieht Audgar mit ihnen und jetzt nur noch wenigen ${ }^{89}$ Getreuen an den Langobardenhof, $\mathrm{zu}$ dem die Franken unter Karl Martell gutnachbarliche, unter Pippin überwiegend feindliche, nach seinem Tode aber wieder sehr enge Beziehungen unterhalten

88 Hierzu und zum Folgenden Lejeune $(1948,67)$ mit Verweis auf Delaruelle, «Charlemagne, Carloman, Didier et la politique du mariage franco-lombard», Revue historique 170 (1932), 220. 89 Cum aliquibus paucis Francis sagen die zeitlich nächststehenden Annales Laurissenses (MGH, Scriptores 1.148). 
hatten, der also jedenfalls nicht als ihr Erbfeind gelten konnte. Zwar bedingt die Ankunft der Flüchtlinge in Italien zwischen beiden Reichen neue Spannungen; doch da Karl fast gleichzeitig seine langobardische Gattin verstößt, zeigt er, daß diese Spannungen ihm geradezu willkommen sind. Noch ist Karl in Sachsen beschäftigt; aber Audgar weiß aus Pippins Zeiten, daß die militärische Konfrontation auf längere Sicht unvermeidlich und daß ein einiges Frankenreich dem Langobardenreich überlegen ist. Will er die fränkische Einigkeit noch rechtzeitig schwächen, so muß er seinen letzten Trumpf ausspielen: er muß die Karlmannssöhne vom Papst zu Frankenkönigen salben lassen. ${ }^{90}$ Hadrian weigert sich, und Audgar rückt inmitten eines langobardischen Heeres auf Rom. Erst damit wird er rechtlich zum Verräter: Karl ist jetzt durch Akklamation der überwältigenden Mehrheit der bisherigen Untertanen Karlmanns legaler König aller Franken, und wer andere Frankenkönige neben ihm einsetzen will, begeht Hochverrat. Noch hat Audgar nicht gegen Landsleute gekämpft; doch bleibt ihm auch dies in dem folgenden Krieg zwischen Karl und Desiderius kaum erspart: selbst wenn er manuell nie die Waffe geführt haben sollte, darf Karl ihn rechtlich als kriegsführende Partei behandeln, spätestens nachdem er sich vorübergehend mit Adelgis in Verona verschanzt hat. Als er sich schließlich mit seinen Schützlingen dem Sieger unterwirft, ist er buchstäblich einer der letzten Franken, die den Weg zu Karl finden.

Andererseits verdient Karl sehr wohl das ihm in der Vita Hadriani verliehene Prädikat benignissimus: er hätte Audgar nach Kriegsrecht zum Tode verurteilen lassen können. Insofern kann man durchaus von einer Versöhnung sprechen, wie der Autor der Vita Hadriani sie ja auch durch die Worte eosque recipiens andeutet.

«Isolation» und «Versöhnung»: in diesen beiden Stichworten schon des Jahres 773 liegt die spätere Doppelgesichtigkeit Ogiers beschlossen. Denn von jetzt an waren gegenüber der Erinnerung an Audgar zwei ganz verschiedene Erzählhaltungen möglich.

Entweder ein Erzähler hatte den Mut, sich ausdrücklich die Rebellion Ogiers zum Thema zu nehmen; dann wurde es seine Hauptaufgabe, die fortschreitende Vereinsamung des Rebellen möglichst bildkräftig darzustellen. Und da die Epik stärker aus der Handlung als aus der Diktion lebt, mußten diese bildhaften Elemente ihren Platz in der Handlung selbst finden: es sind die Flucht durch halb Italien längs der Pilgerstraße, der allmähliche Verlust der Getreuen, der einsame siebenjährige Widerstand in der Toskana, schließlich als Antiklimax die Überwältigung des erschöpft Schlafenden in einem friedlichen

90 Cf. z. B. die Vita Hadriani im Liber Pontificalis 488, 493, 495; Bédier (1926, 195 ss.). 
Tal. Orts- und Zeitangaben mögen durch epische Vergrößerung unhistorisch geworden sein, die psychologische «Relevanz» der Erzählung ist über Jahrhunderte dieselbe geblieben. ${ }^{91}$ Freilich machte sich in der ersten Hälfte des 12. Jh. selbst in dieser Tradition der Wunsch bemerkbar, Karl zu schonen: indem das Thema der «verfolgten Kinder» von dem neuen Schachspielthema rasch überschattet wurde, konzentrierten sich die Affekte des Hörers auf den mißratenen Sohn Charlot statt auf Karl.

Oder aber - damit kommen wir zu der zweiten Möglichkeit der Gestaltung - ein Autor zeigte ohnehin keine Neigung, das heikle Rebellionsthema anzupacken, sondern verdrängte es. Als Positiva Audgars blieben aber auch dann die entscheidenden Dienste, die er seinem Volk unter Pippin in Italien geleistet hatte, und die Tatsache einer leidlichen «Versöhnung» mit Karl. Aus diesen Elementen kann ein Autor entweder Ogiers erbauliches Ende thematisieren - so geschehen in Meaux, Kempten und Tegernsee (sowie im Schlußteil der Chevalerie). Oder er beschränkt sich auf den Namen und das allgemeine Prädikat der «Größe» Ogiers und kann dann die Gestalt in beliebigen Epenhandlungen als eine Art überdimensionalen Komparsen einsetzen.

Und ist diese letztere Lösung so ungewöhnlich? Der historische Raimbaut[Radbod] de Frise war einer der gefährlichsten Gegner Karl Martells, Huidelon[Odilo] de Bavière bereitete schon Karl Martell, dann Pippin ständige Schwierigkeiten, Gaifier[-Waifar] de Bordele war der Alptraum der Franken in Pippins zweiter Lebenshälfte und noch beim Regierungsantritts Karls des Großen, Rispeu[-Erispoe] und Salomon de Bretagne standen mit Karl dem Kahlen überwiegend auf dem Kriegsfuß - in der Epik hingegen sind sie sämtlich zu treuen Satelliten «Karls» geworden. Konnte man so sehr von ihren Taten und von ihren genauen Lebensdaten absehen, aber zugleich so zäh an ihren Namen festhalten, warum hat dann Herzog Audgar nicht schon aufgrund seiner unter Pippin geleisteten Dienste ein Anrecht auf intensiveres und positiveres Weiterleben? Insgesamt dürfen wir also auch für die positive Hälfte der frühen Doppelgesichtigkeit Ogiers historische Gründe in Anspruch nehmen.

91 Übrigens haben auch drei Forscher, die nicht dem Neotraditionalismus nahestehen, die Vereinsamung Ogiers als zentrales Thema seiner Tradition sehr wohl erkannt: R. R. Bezzola $(1959,188)$ spricht von Ogier l'idéal du vassal solitaire. Vor allem aber hat der feinhörige A. Adler (1963, 76-119, speziell 100) in den Mittelpunkt seiner immanenten Interpretation die Beobachtung gestellt, daß die wenigen Getreuen Ogiers, «einer nach dem anderen, dahingehen müssen, bis der Held großartig verlassen und einsam dasteht.» Ähnlich schließlich vor kurzem J. Belam (1998, 25-40): nach einer bemühten, aber letztlich unzureichenden Durchleuchtung des historischen Hintergrundes, die in einem Verdikt «real, aber für die Chevalerie ziemlich unerheblich» gipfelt, folgt eine gute Interpretation mit Herausarbeitung des Isolationsthemas, aber als einer vermeintlichen Nouveauté des Dichters. 
Ronald Walpole schrieb: «If, then, the mention of Ogier in the Nota is to be considered proof of the existence of a well developed legend concerning him, it must be the mark of a strangely complex legend containing the incompatible elements of Ogier the rebel and Ogier the faithful vassal of Charlemagne. [...] Such a conclusion is not acceptable.» ${ }^{92}$

Incompatible? Welchen Triumph feiert in diesen Sätzen eine glasklare Mediävistik! Für sie ist jede Epengestalt zunächst böse od er gut. An Walpoles Raisonnement scheint mir nichts willkürlich als eben diese Grundannahme. Ich hoffe umgekehrt gezeigt zu haben, daß nicht nur die Geschichte komplexer war, sondern daß auch die frühe Ogiertradition wesentliche Teile dieser Komplexität einzufangen wußte; daß wir trotz der Untersuchungen von Aebischer und Togeby nicht genötigt sind, prinzipiell (d. h. abgesehen vom Beinamen Danois) abzugehen von dem Bilde eines einheitlichen und historischen Ogier, wie es R. Lejeune und R. Louis entworfen haben; daß Audgars Zeitgenossen zunächst von ihm erzählten, nicht obwohl, sondern weil sie von seinem komplexen Schicksal ergriffen waren, weil sie den Widerspruch zwischen älterer, personengebundener und jüngerer, institutionsgebundener Treue als in ihrer Epoche unaufhebbar erlebten, und weil schließlich diejenigen, die diesen Widerspruch nicht gestalten konnten oder wollten, Ogier das vage Prädikat der «Größe» umso weniger verweigern mochten.

\section{Bibliographie}

Abel, Sigurd/Simson, Bernhard v., Jahrbücher des fränkischen Reiches unter Karl dem Großen, vol. 2, Berlin, Duncker und Humblott, 1883.

Adler, Alfred, Rückzug in epischer Parade, Frankfurt a. M., Klostermann, 1963.

Aebischer, Paul, Le concept d'état latent dans la préhistoire des chansons de geste, Revue

Belge de Philologie et d'Histoire 47 (1969), 789-839.

Aebischer, Paul, La mesnie Doon de Mayence et son plus illustre représentant, Ogier le Danois, in: Mélanges de langue et de littérature médiévales offerts à Pierre Le Gentil, Paris, S.E.D.E.S, 1973, 13-32.

Alexander Neckam, De naturis rerum, ed. Thomas Wright, London, Longman, 1863.

Alonso, Dámaso, La primitiva épica francesa a la luz de una «nota emilianense», RFE 37 (1953), 2-94.

Arnulfi Aurelianensis, Glosule super Lucanum, ed. Berthe M. Marti, Rom, American Academy, 1958.

Barrois, Joseph (ed.), La Chevalerie Ogier de Danemarche, Paris, Techener, 1842 (Nachdruck Genf, Slatkine, 1969).

92 Walpole (1956/57, 8). 
Bartholinus, Thomas, De Holgero Dano qui Caroli Magni tempore floruit dissertatio historica, Kopenhagen, 1677.

Bauerreiß, Romuald, Die älteste Kirche von Tegernsee und ihre Stifter, Studien und Mitteilungen zur Geschichte des Benediktinerordens 60 (1946), 9-26.

Becker, Philipp August, Ogier von Dänemark, ZfSL 64 (1940), 67-88.

Bédier, Joseph, Les légendes épiques, Paris, Champion, vol. 2, 31926, vol. 4, ${ }^{3} 1929$.

Belam, Judith, Ogier le Danois: making use of a legend, in: Ailes, Marianne (ed.), Reading around the Epic: a Festschrift in Honour of Professor Wolfgang von Emden, London, King's College, 1998, 25-40.

Bender, Karl-Heinz, König und Vasall. Untersuchungen zur Chanson de geste des XII. Jahrhunderts, Heidelberg, Winter, 1967.

Bezzola, Reto R., À propos de la valeur littéraire des Chansons féodales, in: La Technique Littéraire des Chansons de Geste. Actes du Colloque de Liège 1957, Paris, 1959, 183-196.

Böhner, Kurt, Die fränkischen Altertümer des Trierer Landes, Berlin, Mann, 1958.

Cerf, Barry, Ogier le Danois and the Abbey of Saint Faro of Meaux, RR 1 (1910), 1-12.

Chaume, Maurice, Le sentiment national bourguignon de Gondebaud à Charles le Téméraire, in: Mémoires de l'Académie de Dijon, vol. 1, Dijon, Bernigaud, 1922, 195-285.

Chaume, Maurice, Les origines du duché de Bourgogne, vol. 1, Dijon, Jobard, 1925.

Chevalerie Ogier de Danemarche, s. Barrois und Eusebi.

Collino, Giovanni (ed.), Le carte della Prevostura d'Oulx, Pinerolo 1908.

Depoin, Jules, Études sur le Luxembourg à l'époque carolingienne (Suite), Ons Hémecht

[Luxemburg] 12 (1906), 461-467.

Devailly, Guy (ed.), Le cartulaire de Vierzon, Paris, P.U.F., 1963.

de Vries, Jan, De Wikingen in de lage landen bij de zee, Haarlem, Willink, 1923.

Dhondt, Jan, De Forestiers van Vlaanderen, Bulletin de la Commission royale d'histoire [Bruxelles] 105 (1940), 282-305.

Dümmler, Ernst, Geschichte des ostfränkischen Reiches, 3 vol., Leipzig ${ }^{2} 1887-88$ (Nachdruck Hildesheim, Olms, 1960).

Eusebi, Mario (ed.), La Chevalerie Ogier de Danemarche, Mailand, Ist. Ed. Cisalpino, 1963.

Ewig, Eugen, Milo et eiusmodi similes, in: Stadt Fulda (ed.), Sankt Bonifatius, 754-1954, Gedenkgabe zum 1200. Todestag, Fulda, Parzeller, 1954.

Fliche, Augustin, Le règne de Philippe Ier, Paris 1912 (Nachdruck Genf, Slatkine, 1975).

Förstemann, Ernst, Altdeutsches Namenbuch, vol. 1: Personennamen, Bonn ${ }^{2} 1900$ (Nachdruck München, Fink, 1966), Ergänzungsband von Henning Kaufmann, München, Fink, 1968.

Frank, István, L'affaire de Roncevaux, in: Coloquios de Roncesvalles, Saragossa, Edición «El Noticiero», 1956, 212-223.

Gabotto, Ferdinando, Il conte di Tortona Alpgario e la famiglia di re Berengario I e di Uggieri il Danese, Archivio Storico Italiano 74 (1916), vol. 2, 150-167.

Gale, David A., The Seax, in: Sonia Ch. Hawkes (ed.), Weapons and Warfare in Anglo-Saxon England, Oxford, 1989, 71-83.

Gallia Christiana, vol. XVI, besorgt von Jean Barthélemy Hauréau, Paris, 1865.

Germania Pontificia, vol. II 1, ed. Albert Brackmann, Berlin, Weidmann, 1923.

Gesta abbatum Fontanellensium s. Pertz, Löwenfeld und Lohier/Laporte.

Guichenon, Samuel (ed.), Bibliotheca Sebusiana, Lyon 1660.

Hirsch, Hans, Die unechten Urkunden Papst Leos VIII. für Einsiedeln und Schuttern, Neues

Archiv 36 (1911), 397-413.

Histoire littéraire de la France, XX, Paris, 1842. 
Jacobsen, Peter Christian (ed.), Die Quirinalien des Metellus von Tegernsee, Leiden, Brill, 1965.

Jean d'Outremeuse, Le Myreur des Histors, Fragment du Second Livre, ed. André Goosse, Brüssel, Académie Royale de Belgique, 1965.

Karlamagnús Saga: branches I, III, VII et IX, nach Knud Togeby und Pierre Halleux ed. Agnete Loth, Kopenhagen, Reitzels, 1980.

Kienast, Walther, Der Herzogtitel in Frankreich und Deutschland, München, Oldenbourg, 1968.

Knudsen, Gunnar/Kristensen, Marius/Hornby, Rikard, Danmarks gamle Personnavne, vol. 1, Kopenhagen, Dansk Historisk Håndbogsforlag, 1936.

Lang, J./Ager, B. Swords of the Anglo-Saxon and Viking Periods in the British Museum: a Radiographic Study, in: Hawkes, Sonia Ch. (ed.), Weapons and Warfare in Anglo-Saxon England, Oxford 1989, 85-122.

Langlois, Ernest, Table des noms propres de toute nature compris dans les chansons de geste imprimées, Paris, Bouillon, 1904.

Laux, Friedrich, König Raedwalds Grab bei Sutton Hoo, in: Ahrens, Claus (ed.), Sachsen und Angelsachsen, Hamburg, 1978, 483-493.

Lecoy, Felix, Rez. Alonso (s. oben), Romania 76 (1955), 254-269.

Le Gentil, Pierre, Ogier le Danois, héros épique, Romania 78 (1957), 199-233.

Leibniz, Gottfried Wilhelm, Annales Imperii occidentis Brunsvicenses, ed. Georg Heinrich Pertz, Hannover, Hahn, 1843.

Lejeune, Rita, Recherches sur le thème: Les chansons de geste et l'histoire, Liège, 1948.

Lemarignier, Jean-François, Recherches sur l'hommage en marche et les frontières féodales, Lille, Bibliothèque universitaire, 1945.

Liber Pontificalis, ed. Louis Duchesne, vol. 1, Paris, 1886 (Nachdruck Paris, Boccard, 1955).

Lohier, Dom F./Laporte, J. (ed.), Gesta sanctorum patrum Fontanellensis coenobii (Gesta abbatum Fontanellensium), Rouen/Paris, Lestringant/Picard, 1936.

Lombard, Maurice, Les métaux dans l'ancien monde, Paris, Mouton, 1974.

Lot, Ferdinand/Halphen, Louis, Le Règne de Charles le Chauve, vol. 1 (a. 840-851), Paris, Champion, 1909.

Lot, Ferdinand, Études critiques sur l'Abbaye de Saint-Wandrille, Paris, Champion, 1913.

Lot, Ferdinand, La légende d'Ogier le Danois, Romania 66 (1940), 238-253 (Wiederabdruck in F.L., Études, 280-292).

Lot, Ferdinand, Études sur les légendes épiques françaises, Paris, Champion, 1958.

Louis, René, De l'Histoire à la légende, vol. 1: Girart, comte de Vienne (... 819-877) et ses fondations monastiques, Auxerre, Imprimerie moderne, 1946.

Louis, René, L'épopée française est carolingienne, in: Coloquios de Roncesvalles, Saragossa, Edición «El Noticiero», 1956, 327-460.

Löwenfeld, Samuel (ed.), Gesta abbatum Fontanellensium, Hannover, Hahn, 1886.

Luchaire, Achille, Louis VI le Gros, annales de sa vie et de son règne, Paris, Picard, 1890. Manteyer, Georges de, La Provence du ler au XII siècle, Paris, Picard, 1908.

Manteyer, Georges de, Les Origines du Dauphiné de Viennois, Gap, Jean et Peyrot, 1925.

Martinet, Suzanne, Le grand duc Autcarius préfigure d'Ogier le Danois, in: Buschinger, Danielle (ed.), Histoire et littérature au Moyen Age. Actes du Colloque du Centre d'Etudes Médiévales de l' Université de Picardie (Amiens 20-24 mars 1985), Göppingen, Kümmerle, 1991, 291-300.

Menéndez Pidal, Gonzalo, Sobre el escritorio Emilianense en los siglos X a XI, Boletín de la Real Academia de la Historia 143 (1958), 7-19. 
Menéndez Pidal, Ramón, La Chanson de Roland et la tradition épique des Francs, Paris, Picard, ${ }^{2} 1960$.

Merlet, Lucien, Dictionnaire topographique du Département d'Eure-et-Loir, Paris, Impr. Impériale, 1861.

Moisan, André, Répertoire des noms propres de personnes et de lieux cités dans les chansons de geste françaises et les œuvres étrangères dérivées, 2 Teile in 5 Bänden, Genf, Droz, 1986.

Mone, Franz Joseph, Übersicht über die niederländische Volks-Literatur älterer Zeit, Tübingen, Fues, 1838.

Mühlbacher, Engelbert (ed.), Diplomata Karolinorum I (Monumenta Germaniae Historica), Hannover, Hahn, 1906.

Oelsner, Ludwig, Jahrbücher des fränkischen Reiches unter König Pippin, Berlin, Duncker und Humblot, 1871.

Oppermann, Otto, Kritische Studien zur älteren Kölner Geschichte, vol. 1: Die Fälschungen des Oliver Legipont zur Überlieferung von St. Martin, Westdeutsche Zeitschrift für Geschichte und Kunst [Trier] 19 (1900), 271-344.

Paris, Gaston, Rez. Pio Rajna, Le Origini dell' epopea francese (Florenz 1884), Romania 13 (1884), 598-627.

Pedersen, Christiern, Danske Skrifter, ed. C. J. Brandt, vol. 5., Kopenhagen, 1856.

Périn, Patrick/Kazanski, Michel, (a) Das Grab Childerichs I., (b) Männerkleidung und Bewaffnung im Wandel der Zeit, in: Wieczorek, Alfried, et al. (edd.), Die Franken - Les Francs, Mainz, Zabern, ${ }^{2} 1997$, vol. 1, 173-182 (= 1997a) bzw. vol. 2, 707-711 (= 1997b).

Pertz, Georg Heinrich (ed.), Gesta abbatum Fontanellensium, in: Monumenta Germaniae Historica, Scriptores II, Hannover, Hahn, 1829, 270-300.

Peters, Paul (ed.), Die Quirinalien des Metellus von Tegernsee, (Diss.), Greifswald, 1913.

Rajna, Pio, Contributi alla storia dell'epopea e del romanzo medievale, Romania 18 (1889), $1-69$.

Riezler, Siegmund, Naimes von Bayern und Ogier der Däne, in: SB phil.-hist. Kl. AdW, München 1892, 713-788.

Rivautella, Antonio/Berta, Francesco (edd.), Ulciensis Ecclesiae Chartarium, Turin, 1753.

Rosellini, Aldo, Onomastica epica Francese in Italia nel medioevo, Romania 79 (1958), 253-267.

Ruggieri, Ruggero M., Les Lombards dans les Chansons de geste, in: Quatrième Congrès International de la Société Rencesvals, Actes et Mémoires, Heidelberg, Winter, 1969, 37-45.

Rychner, Jean, La Chanson de geste. Essai sur l'art épique des jongleurs, Genf, Droz, 1955.

Schreibmüller, Hermann, Die Ahnen Kaiser Konrads Il. und Bischof Brunos von Würzburg, in: Herbipolis Jubilans (= Würzburger Diözesangeschichtsblätter 14/15), Würzburg, 1952, 174-233.

Siegmund, Frank, Kleidung und Bewaffnung der Männer im östlichen Frankenreich, in: Wieczorek, Alfried, et al. (edd.), Die Franken - Les Francs, Mainz, Zabern, ${ }^{2} 1997$, vol. 2, 691-706.

Spore, Palle, Oger li Daneis est-il Danois?, in: Boysen, Gerhard/Moestrup, Jorn (edd.), Études de linguistique et de littérature dédiées à Morten Nøjgaard, Odense 1999, 551-555.

Spruner, Karl/Menke, Theodor, Handatlas für die Geschichte des Mittelalters und der neueren Zeit, Gotha, ${ }^{3} 1880$.

Stein, Henri, Dictionnaire topographique du Département de Seine-et-Marne, Paris, Impr. nationale, 1954. 
Terrebasse, Alfred de, Notice sur les Dauphins de Viennois, in: Euvres posthumes de A. de Terrebasse, Vienne, Savigné, 1875.

Togeby, Knud, Ogier le Danois, RRo 1 (1966), 110-119.

Togeby, Knud, Ogier le Danois dans les littératures européennes, Kopenhagen, Munksgaard, 1969.

Vogel, Walther, Die Normannen und das Fränkische Reich bis zur Gründung der Normandie (799-911), Heidelberg, Winter, 1906.

Voretzsch, Carl, Über die Sage von Ogier dem Dänen und die Entstehung der Chevalerie Ogier, Halle, Niemeyer, 1891.

Waquet, Henri (ed.), Suger, Vie de Louis VI de Gros, Paris, Les Belles Lettres, 1929.

Walpole, Ronald N., The Nota Emilianense, New Light (But How Much?) on the Origins of the Old French Epic, RPh 10 (1956/57), 1-18.

Werner, Karl Ferdinand, Untersuchungen zur Frühzeit des französischen Fürstentums, Welt als Geschichte 18 (1958), 258-289, 19 (1959), 146-193, 20 (1960), 87-119.

Werner, Karl Ferdinand, Bedeutende Adelsfamilien im Reich Karls des Großen, in: Braunfels, Wolfgang, et al. (edd.), Karl der Große, vol. 1, Düsseldorf, Schwann, 1965. 
